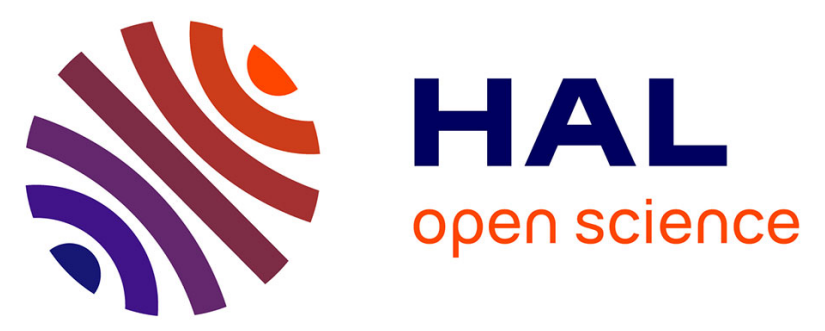

\title{
Length of the Core Forming Block Effect on Fusion and Fission Dynamics at Equilibrium in PEO-PPO-PEO Triblock Copolymer Micelles in the Spherical Regime
} G. Landazuri, V.V.A. V A Fernandez, J.F.A. F A Soltero, Yahya Rharbi

\section{- To cite this version:}

G. Landazuri, V.V.A. V A Fernandez, J.F.A. F A Soltero, Yahya Rharbi. Length of the Core Forming Block Effect on Fusion and Fission Dynamics at Equilibrium in PEO-PPO-PEO Triblock Copolymer Micelles in the Spherical Regime. Macromolecules, 2021, 54 (5), pp.2494-2505. 10.1021/acs.macromol.0c01520 . hal-03453846

\author{
HAL Id: hal-03453846 \\ https://hal.science/hal-03453846
}

Submitted on 28 Nov 2021

HAL is a multi-disciplinary open access archive for the deposit and dissemination of scientific research documents, whether they are published or not. The documents may come from teaching and research institutions in France or abroad, or from public or private research centers.
L'archive ouverte pluridisciplinaire HAL, est destinée au dépôt et à la diffusion de documents scientifiques de niveau recherche, publiés ou non, émanant des établissements d'enseignement et de recherche français ou étrangers, des laboratoires publics ou privés. 


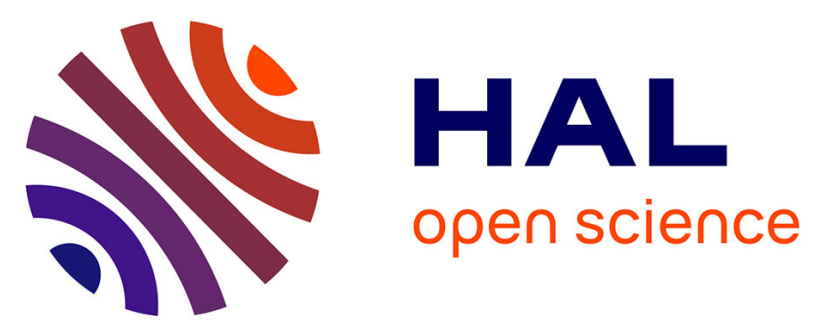

\section{Length of the Core Forming Block Effect on Fusion and Fission Dynamics at Equilibrium in PEO-PPO-PEO Triblock Copolymer Micelles in the Spherical Regime}

G. Landazuri, Yahya Rharbi, J.F.A. Soltero, V.V.A. Fernandez

\section{- To cite this version:}

G. Landazuri, Yahya Rharbi, J.F.A. Soltero, V.V.A. Fernandez. Length of the Core Forming Block Effect on Fusion and Fission Dynamics at Equilibrium in PEO-PPO-PEO Triblock Copolymer Micelles in the Spherical Regime. Macromolecules, American Chemical Society, 2021, 54 (5), pp.2494-2505. 10.1021/acs.macromol.0c01520 . hal-03453846

\section{HAL Id: hal-03453846 \\ https://hal.archives-ouvertes.fr/hal-03453846}

Submitted on 28 Nov 2021

HAL is a multi-disciplinary open access archive for the deposit and dissemination of scientific research documents, whether they are published or not. The documents may come from teaching and research institutions in France or abroad, or from public or private research centers.
L'archive ouverte pluridisciplinaire HAL, est destinée au dépôt et à la diffusion de documents scientifiques de niveau recherche, publiés ou non, émanant des établissements d'enseignement et de recherche français ou étrangers, des laboratoires publics ou privés. 
KEYWORDS: dynamic, fusion, fission, copolymer micelles, amphiphilic copolymers.

\begin{abstract}
Due to their slow kinetics, the dynamical pathways of block copolymer micelles are as important as the copolymer architecture, particularly when making self-assembled nanostructures. Two types of dynamical pathways could govern these dynamics: insertion/expulsion of copolymer chains and fusion/fission of micelles. However, quantifying and understanding the fusion and fission processes remains very limited in copolymer micelles, especially at equilibrium. In this article, it was demonstrated the use of a fluorescent technique, using randomization of a highly hydrophobic pyrene derivative between micelles, as a tool to quantify the fusion and fission at equilibrium in a series of triblock copolymers micelles Poly(ethylene oxide)-poly(propylene oxide)-poly(ethylene oxide) in aqueous solution. The temperature dependence of fusion and fission is investigated for copolymers with various core block lengths (NPPO) in the spherical regime. Fusion and fission rates were found to strongly decrease with increasing the core block length. The dependence of the fission rate on NPPO is analyzed in terms of thin corona and starlike micelle models which suggest that fission is mainly dominated by the core interfacial tension as predicted by Halperin et al. The comparison between fission and expulsion kinetics and their dependence on PPO block is also reported. Finally, fusion is found to follow the same temperature and core length dependencies as fission, which is an indication that the interfacial tension plays a relevant role in the fusion kinetic.
\end{abstract}




\section{INTRODUCTION}

Nanoscale morphologies such as spherical micelles, elongated rod-like, bilayer vesicles, etc., are normally achieved by controlling the self-assembly of block copolymers. ${ }^{1-3}$ When block copolymers are integrated into emerging technologies, full control of their elaboration and their temporal evolution becomes crucial. ${ }^{1,2}$ Drug delivery, nanoreactors, cosmetic and nanolithography are examples where the control of the block copolymer morphology is essential for the process. ${ }^{1-3}$ This has motivated decades of research activities to establish the know-how for designing these structures either through synthesis of novel macromolecular architectures or via tuning the copolymer interactions. ${ }^{4,5}$

Besides the macromolecular architecture design, which plays a substantial role in the morphology control of block copolymers, their dynamical pathways are crucial as well to control the nanoscale morphologies. ${ }^{3,6-14}$ Indeed, the self-assembly of block copolymers in selective solvents is highly dependent on the polymer dynamic, particularly when the surface tension of the core-forming block is high, which can even trap the structure in metastable states..$^{72-15}$ The kinetic pathways are as important in the self-assembly as the dynamic itself, particularly in the trapped states. ${ }^{12-15}$ In analogy to small surfactant molecules, copolymer micelles involve two classes of dynamic processes: ${ }^{\cdot 56-24} i$ ) an individual process, which includes insertion-expulsion of copolymer chains to and from the micelles, ${ }^{16,23,25-32}$ and $\mathrm{ii}$ ) a collective process, which involves the fusion and fission of micelles. ${ }^{19,33-41}$

Acquiring the appropriate method for discriminating the kinetical pathways remains one of the main tasks toward understanding the micellar dynamic. 6,11,41-45 This task becomes even more challenging when it comes to block copolymer micelles in a selective solvent due to its slow dynamic. 9,31 The kinetic measurements could be carried out either in out-of-equilibrium $5,11,28,29,38,46,16-$ ${ }^{23}$ or in an equilibrium pathway. ${ }^{25,26,30,43,47-53}$ Most of the knowledge about the dynamic processes of block copolymer micelles comes from out-of-equilibrium experiments which are usually conducted by inducing a rapid change in the environmental conditions using stimuli such as temperature-jump, pH-jump, solvent jump, while the return to the new equilibrium is monitored. 5,11,28,29,38,46,16-23 Timeresolved light scattering is used to probe the structural evolution of these micelles between the different equilibrium states either from unimer-micelles, spherical-to-cylindrical micelles or vice versa. ${ }^{18,28,29}$ These experiments give trends of the unimer insertion and expulsion behavior and suggest the existence of the collective mechanisms of fusion and fission from the dependence of the kinetic life 
time on the concentration of copolymer micelles. Time-resolved neutron and X-ray scattering were also used for this task giving more details on the structural aspect of these kinetic processes. ${ }^{11}$

Although the out-of-equilibrium kinetic could be instructive for these systems, it does not give a true picture of the intrinsic dynamical pathways of the block copolymer micelles, particularly at equilibrium. This requires a direct probing and quantifying of all the dynamical processes at equilibrium. 25,26,30,43,47-53 Time-resolved neutron scattering with mixtures of deuterated and hydrogenated copolymers in selective solvent gives the basis of the kinetic behavior of the insertionexpulsion of copolymer chains at equilibrium. ${ }^{25,26,30,43,47-53}$ Similarly, time-resolved fluorescence technique with fluorescently labeled copolymer chains has been used to gain insight on the insertionexpulsion in copolymer micelles. ${ }^{45,54}$ However, these equilibrium techniques were found to be irrelevant for probing the fusion/fission, because no dependence of the copolymer concentration was detected. ${ }^{45}$ The fusion/fission mechanisms manifest mainly in kinetics involving morphological transitions such as sphere-to-cylinder or cylinder-to-sphere. ${ }^{28,29}$ On the other hand, time-resolved fluorescence experiment using a highly hydrophobic probe was found to be pertinent in quantifying fusion and fission mechanisms in surfactant micelles. ${ }^{35,36}$ The exchange of solutes between micelles shares the same pathways with the exchange of surfactant molecules (Chart 1). This technique uses the inability of these probes to exchange via the aqueous phase and only exchange via fusion of two micelles or fission of one micelle. By using such a technique and the appropriate dye, one can quantify fusion and fission rate in a pseudo-equilibrium state with a rate from millisecond to hours in surfactants..$^{35,36}$ however, this technique applied to block copolymer micelles remains a challenge because of the extreme slow kinetics of the hydrophilic copolymer micelles in water, when the core surface tension is high. Pluronic copolymers were found to be good candidates for such methodologies because of the fast exchange mechanism with insertion and expulsion in the range of milliseconds and fusion and fission in the range of minutes to hours. Indeed, this technique shows that fusion and fission takes place in block copolymer micelles at equilibrium. ${ }^{55}$ 


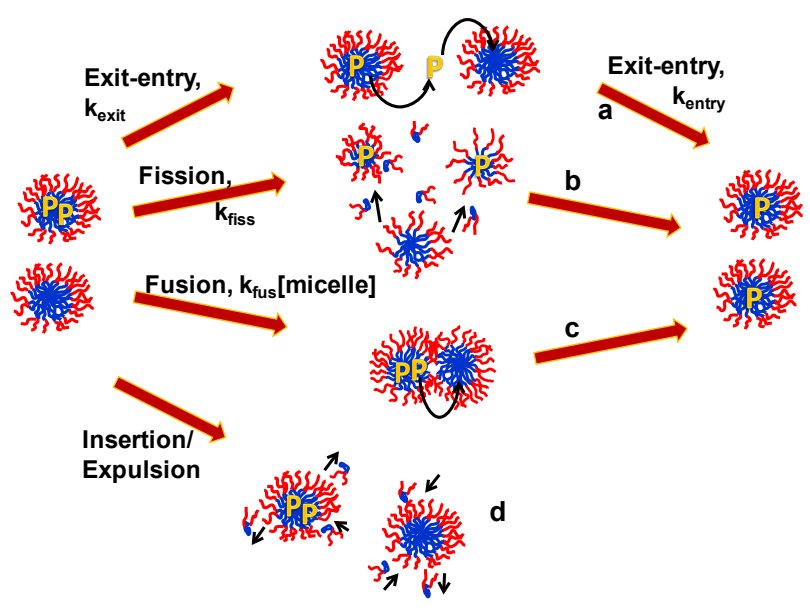

Chart 1 . Scheme depicting the various mechanisms in which the probes $(\mathrm{P})$ and copolymer chains exchange between micelles: a) exit-entry of the probe, b) fission-growth, c) fusion-fission and d) insertion-expulsion of individual chains.

Here fusion and fission mechanisms at equilibrium are quantified in a series of triblock copolymers (Poly(ethylene oxide)-poly(propylene oxide)-poly(ethylene oxide)) with varying the poly(propylene oxide) length and different temperatures, all in the spherical regime. The present work showed that fission is highly sensitive to the core block length with a rate $\mathrm{k}_{\mathrm{iss}}$, decreasing by five orders of magnitude for core lengths between 30-60. The fission rate dependence on the core length could be described using diblock models for the thin corona and starlike micelle. This also shows that fission is mainly dominated by the interfacial tension, as predicted by Haleperin and Alexander. ${ }^{37}$ The difference between fission and expulsion rates depends on the core forming block and can also be described in terms of these models. On the other hand, fusion and fission are found to exhibit the same temperature and core length dependencies, demonstrating that the interfacial tension energy plays an important role in fusion kinetics. Fusion/fission was also found to generate single exponential decays even in polydispersed copolymers. This is explained by fact that the fusion and fission activation energies are time-averaged via rapid chain randomization between micelles.

\section{EXPERIMENTAL}

Materials.

Triblock copolymer Pluronics P103 ( $\left.\mathrm{PEO}_{17} \mathrm{PPO}_{60} \mathrm{PEO}_{17}\right)$, P84 ( $\left.\mathrm{PEO}_{19} \mathrm{PPO}_{43} \mathrm{PEO}_{19}\right)$, and L64 $\left(\mathrm{PEO}_{13} \mathrm{PPO}_{30} \mathrm{PEO}_{13}\right)$ were obtained from BASF and used as received. Gas permeation chromatography (GPC) was used for the molecular weight characterization, obtaining $\mathrm{Mw}=4.95$ 
$\mathrm{kg} / \mathrm{mol}$ with a polydispersity of 1.72 for P103 and $4.2 \mathrm{~kg} / \mathrm{mol}$ in P84 and $2.90 \mathrm{~kg} / \mathrm{mol}$ in L64. Double de-ionized water was used in the preparation of all solutions. The dissolution of Pluronic in water was carried out by gentle agitation of copolymer/water solution for at least $24 \mathrm{~h}$, at room temperature (25 ${ }^{\circ} \mathrm{C}$ ). Pyrene (Sigma-Aldrich) was used as received. The synthesis of the probe 1-pyrenyl-octadecanone $\mathrm{C}_{34} \mathrm{H}_{44} \mathrm{O}\left(\mathrm{PyC}_{18}\right)$ was carried out through Friedel-Crafts acylation of pyrene using stearoyl chloride in dichloroethane in the presence of aluminum chloride $\left(\mathrm{AlCl}_{3}\right) .{ }^{56}$

Solubilization of PyC $C_{18}$ probe in the copolymer micelles. The solubilization of $\mathrm{PyC}_{18}$ in copolymer micelles was achieved by heating a copolymer solution $(20 \mathrm{~g} / \mathrm{L})$, containing a trace of $\mathrm{PyC}_{18}$ at $85^{\circ} \mathrm{C}$ and strongly agitating the solution for 10 minutes with a mechanical shaker Vortex genie 2 model $\mathrm{G}$ 650 at its maximum frequency $(>10 \mathrm{~Hz})$. The non-dissolved probe was removed by centrifuging the solution at $5000 \mathrm{rpm}$ for 15 minutes at $25{ }^{\circ} \mathrm{C}$. The Fluoroog-3 (FL3-22) of Horiba Jobin Yvon spectrometer was used in the fluorescence measurements.

Copolymer Micelle Characterization. Time-resolved fluorescence measurements of pyrene in copolymer micelles were used to estimate the micelles aggregation number $\mathrm{N}_{\text {agg. }}$. Pyrene was solubilized in the polymer micelles at $25^{\circ} \mathrm{C}$ for more than $24 \mathrm{~h}$. The non-dissolved pyrene aggregates were removed by centrifuging the solution at $5000 \mathrm{rpm}$. Fluorescence decay profiles of excited pyrene were measured by the single-photon-timing technique with $\lambda_{e x}=338 \mathrm{~nm}$ and $\lambda_{\mathrm{em}}=375 \mathrm{~nm}$. The excitation source was a coaxial flash lamp filled with deuterium. Fluorescence decay profiles were fitted to the Tachiya-Infelta Poisson quenching model. ${ }^{57-60}$

$$
I(t)=I_{0} e^{-\frac{t}{\tau_{0}}-\langle n\rangle\left(1-e^{-k_{Q} t}\right)}
$$

where $I_{0}$ is the intensity at time zero, $\tau_{0}$ is unquenched lifetime, $\langle n\rangle$ is the average number of molecules of pyrene per micelle, and $k_{0}$ the pseudo-first-order rate constant for excimer formation. $\tau_{0}$ is estimated from fitting the decay of low [Py] to an exponential expression and $\langle n\rangle=[\mathrm{Py}] N_{\mathrm{agg}} /([\mathrm{P} 103]-\mathrm{cmc})$. The aggregation number $\mathrm{N}_{\mathrm{agg}}$ was calculated from the slope of the plot of $\langle\mathrm{n}\rangle$ vs $\left[\mathrm{P}_{\mathrm{y}}\right]$ concentration.

Dynamic light scattering (DLS) was used to measure the hydrodynamic radius of the micelles $\mathrm{R}_{\mathrm{h}}$. DLS was measured in a Malvern zetasizer 5000 apparatus equipped with a 7132 Multi-bit correlator 
and multi-angle goniometer. The scattering intensity was measured through a $400 \mu \mathrm{m}$ pinhole at $90^{\circ}$. The hydrodynamic radius $\mathrm{R}_{\mathrm{h}}$ was estimated using the cumulants fits method.

Kinetic experiments. Copolymers solutions $(20 \mathrm{~g} / \mathrm{L})$ containing $\mathrm{PyC}_{18}$ were mixed with probefree copolymer solutions (at different concentrations) in a temperature-controlled home-built stoppedflow at temperatures between the critical micelle temperature (CMT) and onset temperature to form rod like micelles. The time decay of pyrene fluorescence was followed using a spectrofluorometer Fluorolog-3. The ratio copolymer/PyC $\mathrm{C}_{18}$ and probe-free copolymer was $1 / 20$. The wavelength of excitation was $344 \mathrm{~nm}$ and the emission was $\lambda_{\mathrm{em}}=375.5 \mathrm{~nm}$ for the monomer, and $\lambda_{\mathrm{em}}=480 \mathrm{~nm}$ for the excimer. The time decays were fitted to a single exponential expression $I_{E}=I_{E 0} \exp \left(-k_{\text {decay }} t\right)+I_{E 1}$ for the excimer emission and $I_{M}=I_{M 0} \exp \left(-k_{\text {decay }} t\right)+I_{M 1}$ for the monomer one, where $k_{\text {decay }}$ is the decay rate.

\section{RESULTS AND DISCUSSION}

\section{Micelle Characterization.}

The time-resolved excimer formation fluorescence decays of pyrene were found to fit accordingly to the Tachiya-Infelta Poisson quenching model (equation 1), which suggests a random Poisson distribution of pyrene between micelles (Figure S1, Supplementary Information). ${ }^{57-60}$ Several methods were used for fitting the decays, yielding slightly different $\mathrm{N}_{\mathrm{agg}}$ and $\mathrm{k}_{\mathrm{Q}}$ values, which were included in the error bar of $\mathrm{N}_{\mathrm{agg}}$ and $\mathrm{k}_{\mathrm{Q}}$. In one set of analyses, all the parameters were set free. In another analysis, the unquenched lifetime $\tau_{0}$ was first recovered from the low pyrene concentration and then injected in the decays fit at higher pyrene concentration to recover the remaining parameters. The recovered average number of pyrene per micelles $\langle n\rangle$ increases linearly with increasing $\left[\mathrm{P}_{\mathrm{y}}\right]$ for P103 (Figure 1). This suggests a constant $\mathrm{N}_{\text {agg }}$ of around $30+/-2.8$ at $25{ }^{\circ} \mathrm{C}$ for $\mathrm{P} 103$, which is similar to 34.8 estimated from neutron scattering experiments. ${ }^{61-64}$ Beyond $33{ }^{\circ} \mathrm{C}$, the copolymer undergoes a transition from sphere to rod. The recovered $\mathrm{k}_{\mathrm{Q}}=7.5 \times 10^{6} \mathrm{~s}^{-1}+/-1.5 \times 10^{6}$ was similar to the values seen in other pluronics. ${ }^{65}$ The unquenched lifetime $\tau_{0}$ was around $203 \mathrm{~ns}$. The dynamic light scattering experiment on P103 showed that P103 forms spherical micelles in water between 25 and $33{ }^{\circ} \mathrm{C}$, with a hydrodynamic radius around $\mathrm{Rh}=8 \mathrm{~nm} .{ }^{29}$ Above $35^{\circ} \mathrm{C}, \mathrm{P} 103$ micelles grew to form rod shape-like micelles when increasing the temperature. With this information, all the experiments were carried out 
in a range of temperatures where micelles are sphere-like. For P84 and L64, this temperature range was 35 to $70^{\circ} \mathrm{C}$ and 35 to $45^{\circ} \mathrm{C}$, respectively. The $\mathrm{N}_{\text {agg }}$ for P84 and L64 was taken from the literature ${ }^{66-}$ 71 as $45\left(35^{\circ} \mathrm{C}\right)$ and $35\left(40^{\circ} \mathrm{C}\right)$ for P84 and L64, respectively, which increased with increasing the temperature. One can find some discrepancy of the $\mathrm{N}_{\mathrm{agg}}$ values in the literature ${ }^{66-71}$; this was included as an error bar in $\mathrm{N}_{\mathrm{agg}}$ and used to estimate the error bar of the fusion rate $\mathrm{k}_{\text {fus }}$.

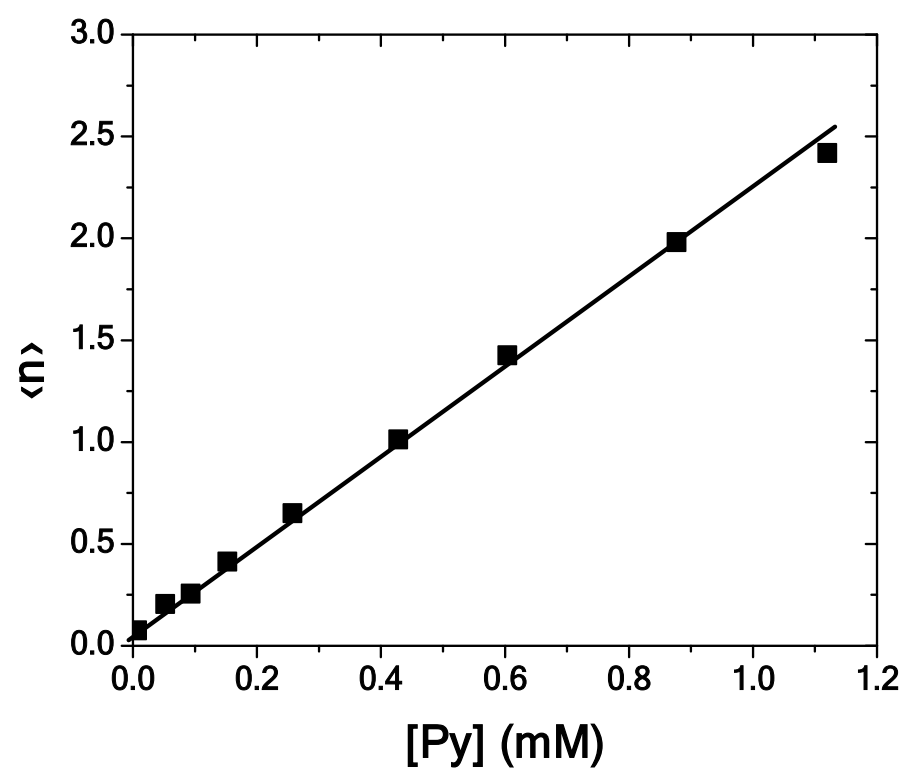

Figure 1. Average number of pyrene molecules per micelle $(\langle n\rangle)$, plotted versus the pyrene concentration for aqueous solutions of $\mathrm{P} 103(50 \mathrm{~g} / \mathrm{L})$ at $25^{\circ} \mathrm{C}$. The $\langle n\rangle$ is calculated by fitting the time-resolved fluorescence decays to equation 1. 


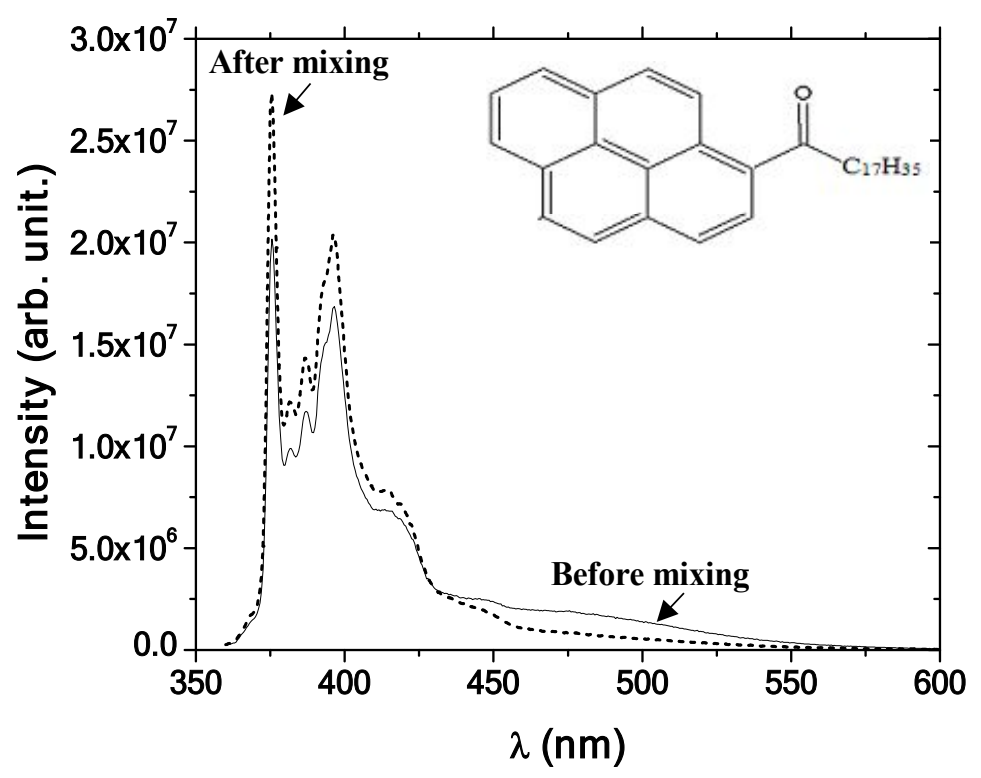

Figure 2. Emission spectra of $\mathrm{PyC}_{18}$ in aqueous solution of $\mathrm{P} 103$ micelles $(20 \mathrm{~g} / \mathrm{L})$ with an average number of pyrene per micelle $\langle n\rangle>0.5$ ("before mixing"). The spectrum "after mixing" is obtained after diluting $0.05 \mathrm{ml}$ of the previous solution with $1 \mathrm{ml}$ of $\mathrm{PyC}_{18}$-free P103 micelles $(20 \mathrm{~g} / \mathrm{L})$. The emission spectrum is measured with the excitation wavelength $\lambda_{\mathrm{ex}}=344 \mathrm{~nm}$. Insert. Molecular structure of the probe $\mathrm{PyC}_{18}$.

Exchange dynamics. In order to achieve a random distribution of the probe between the micelles, the $\mathrm{PyC}_{18}$ was dissolved within the copolymer micelles upon subsequent heating the $\mathrm{PyC}_{18} / \mathrm{P} 103$ solution above the cloud point, and then cooling themto room temperature. ${ }^{55}$ The fluorescence spectra of these solutions exhibited a broad excimer emission at $480 \mathrm{~nm}$ and a monomer emission at 375.5$400 \mathrm{~nm}$ (Figure 2). When these solutions were diluted with $\mathrm{PyC}_{18}$-free copolymer solution and the solutions were left several hours to exchange, the excimer intensity $\left(\lambda_{\mathrm{em}}=480 \mathrm{~nm}, \mathrm{I}_{\mathrm{E}}\right)$ decreased, while the monomer one $\left(\lambda_{\mathrm{em}}=375 \mathrm{~nm}, \mathrm{I}_{\mathrm{M}}\right)$ increased (Figure 2$)$. This suggests that the average number $\mathrm{PyC}_{18}$ per micelle $\left(\langle n\rangle=\left[\mathrm{PyC}_{18}\right] /([\right.$ copolymer $\left.]-c m c) / \mathrm{N}_{\mathrm{agg}}\right)$ declines in the dilution process. The ratio of the excimer to monomer $\left(\mathrm{I}_{\mathrm{E}} / \mathrm{I}_{\mathrm{M}}\right)$ is usually used as a means to verify the random distribution of the probes between micelles. $I_{E} / I_{M}$ was found to increase linearly with increasing the average concentration of $\mathrm{PyC}_{18}\left[\mathrm{PyC}_{18}\right]$ on $\langle n\rangle$, which confirms that $\mathrm{PyC}_{18}$ is randomly distributed as Poisson micelles at all the temperatures investigated. ${ }^{60,72}$ Furthermore, the fit to a Tachiya-Infelta Poisson quenching model of 
the time-resolved excimer formation fluorescence decayed, suggesting a random Poisson distribution of $\mathrm{PyC}_{18}$ for these micelles.

The time dependence of excimer $\mathrm{I}_{\mathrm{E}}(\mathrm{t})$ and monomer $\mathrm{I}_{\mathrm{M}}(\mathrm{t})$ intensities are monitored post mixing the copolymer solution containing $\mathrm{PyC}_{18}$ with $\mathrm{PyC}_{18}$-free solution (Figure 3). The average number of pyrene molecules per micelle $\langle n\rangle$ was kept low $\langle n\rangle<0.5$, to achieve the linearity between $\mathrm{I}_{\mathrm{E}}$ and $\mathrm{I}_{\mathrm{M}}$ and the fraction of micelles bearing two probes $\left(\phi_{2}(t)\right)\left(\mathrm{I}_{\mathrm{E}} \propto \phi_{2}(t), \mathrm{I}_{\mathrm{M}} \propto \phi_{2}(t)\right) .{ }^{73}$

$I_{E}(t)$ and $I_{M}(t)$ can be estimated using the Infelta et al. model ${ }^{60,72}$ by taking into account that the nonradiative excimer dissociation is negligible compared to radiative excimer decays, which is the case of pyrene probes in micelles. $\mathrm{I}_{\mathrm{E}}(\mathrm{t})$ can be written as:

$$
I_{E} \propto \sum_{i=2}^{\infty} \frac{i(i-1) \tau_{0} k_{Q}}{\tau_{0} k_{Q}(i-1)+1} \emptyset_{i}
$$

where $\tau_{0}$ is the unquenched pyrene lifetime, $\mathrm{k}_{\mathrm{Q}}$ is the excimer formation rate and $\phi_{\mathrm{i}}$ the fraction of micelles containing $i$ probe. In the limit of low probe occupancy $\langle n\rangle$, the micelles contain mainly 0,1 or 2 probe molecules, and those containing more than 3 can safely be neglected. In the experimental conditions of this work $\langle n\rangle<0.5$ (thus the time evolution of $\mathrm{I}_{\mathrm{E}}(\mathrm{t})$ ) can be described using micelles containing 2 probes $\phi_{2}(t)$. A similar expression can be derived for $I_{M}(t): 58-60,72$

$$
I_{E}(t) \propto \frac{2 \tau k_{Q}}{\tau k_{Q}+1} \emptyset_{2}(t)
$$




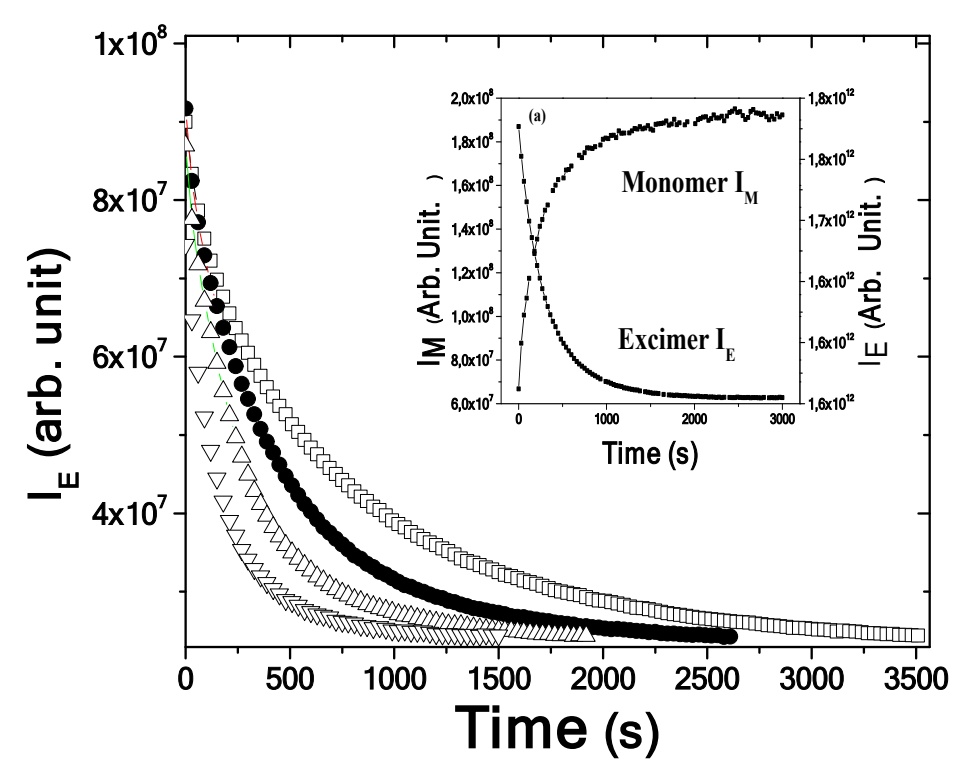

Figure 3. Time-scan experiment of the decrease in the excimer emission $\left(\lambda_{\mathrm{em}}=480 \mathrm{~nm}\right)$ after mixing $0.05 \mathrm{ml}$ of $\mathrm{P} 103$ solution containing $\mathrm{PyC}_{18}$ with $1 \mathrm{ml}$ of a P103 solution at different concentrations 10 $\mathrm{g} / 1(\square), 30 \mathrm{~g} / \mathrm{L}(\bullet), 60 \mathrm{~g} / \mathrm{L}(\triangle)$ and $100 \mathrm{~g} / \mathrm{L}(\nabla)$. The kinetics were monitored at $30^{\circ} \mathrm{C}$. The excitation wavelength $\lambda_{\mathrm{ex}}=344 \mathrm{~nm}$. Inset. Is the time-scan experiment monitoring the decrease in the excimer emission $\left(\lambda_{\mathrm{em}}=480 \mathrm{~nm}\right)$ and the increase of the monomer emission $\left(\lambda_{\mathrm{em}}=375.5 \mathrm{~nm}\right)$ for $20 \mathrm{~g} / \mathrm{L} \mathrm{P} 103$ solution.

The $\mathrm{I}_{\mathrm{E}}(\mathrm{t})$ and $\mathrm{I}_{\mathrm{M}}(\mathrm{t})$ decays exhibited almost an exponential behavior for all the concentrations and temperatures investigated (Figures 3 and 4). The decays were found to be mainly dependent on the concentration of the $\mathrm{PyC}_{18}$-free copolymer solution for all the three copolymers investigated (Figs. 4A and $4 \mathrm{~B}$ respectively). Fitting these decays to the exponential expression yields a rate $\mathrm{k}_{\text {decay }}$, which increases linearly with increasing the concentration of empty micelles ([micelle] $=$ ([copolymer]$(\mathrm{cmc}) / \mathrm{N}_{\mathrm{agg}}$ ) (Figure 5). The $\mathrm{k}_{\text {decay }}$ followed a linear fit as $\mathrm{k}_{\text {decay }}=k_{1}+k_{2}$ [micelle], which suggests the concurrence between second-order kinetics with a rate $\left(k_{2}\right.$ [micelle] $)$ and first-order kinetics with a rate $k_{1}$. 

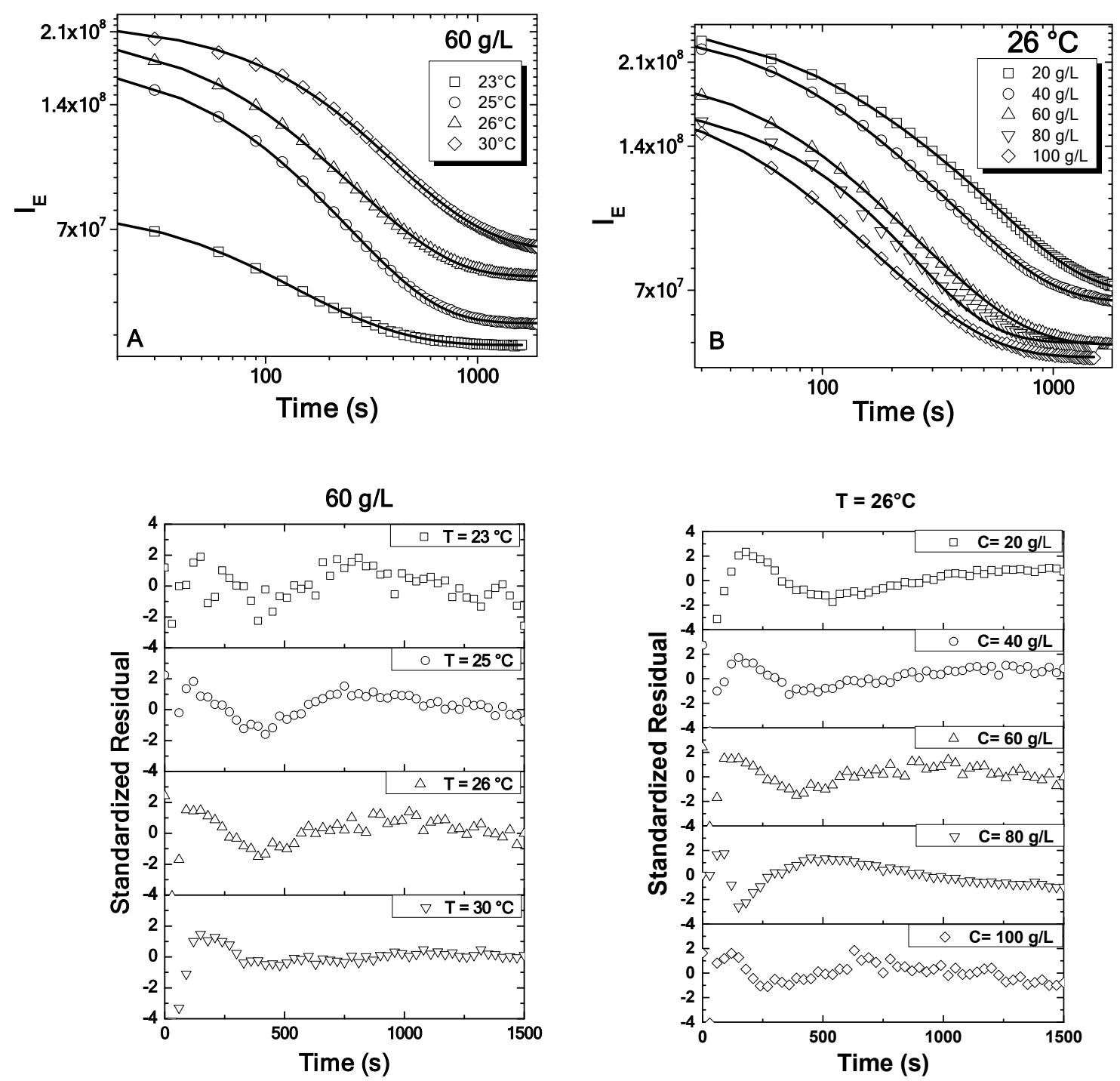

Figure 4. top. Time-scan experiment monitoring the decrease of the excimer emission $\left(\lambda_{\mathrm{em}}=480 \mathrm{~nm}\right)$ A: after mixing $0.05 \mathrm{ml}$ of P103 solution $(60 \mathrm{~g} / \mathrm{L})$ containing $\mathrm{PyC}_{18}$ with $1 \mathrm{ml}$ of a P103 solution (60 g/L) at various temperatures: $23{ }^{\circ} \mathrm{C}(\square), 25{ }^{\circ} \mathrm{C}(\circ), 26{ }^{\circ} \mathrm{C}(\triangle)$ and $30{ }^{\circ} \mathrm{C}(\diamond) .(-)$ The fit to a single exponential expression). B: Excimer decays after mixing $0.05 \mathrm{ml}$ of P103 solution containing $\mathrm{PyC}_{18}$ with $1 \mathrm{ml}$ of a P103 solution at $20(\square), 40(\circ), 60(\triangle) 80(\nabla)$ and $100 \mathrm{~g} / \mathrm{L}(\diamond)$ at a temperature of 26 ${ }^{\circ} \mathrm{C}$. (-) The fit to a single exponential expression. The excitation wavelength $\lambda_{\mathrm{ex}}=344 \mathrm{~nm}$. Bottom: the residuals of the fits to a single exponential expression of the top decays. 
The various probe exchange mechanisms between block copolymer micelles. The transfer of a probe from the full micelle to an empty one takes place through (chart 1) ${ }^{35,36,55:} i$ ) the exit and entry process via the aqueous phase, $i$ ) fission of the full micelles into two micelles each bearing one probe followed by the growth of the fragments and iii) fusion of the full micelles with an empty micelle to form a large micelle "super-micelle" followed by the fission of this "super-micelle" into two proper ones containing each one probe. Although these three processes can be superimposed in the same kinetics, experimentally they can be distinguished through their concentration dependence and the probe polarity $i$ ) The exit-entry process takes place via the exit of the probe from the micelle into the aqueous phase followed by its entry in an empty one. This is a first-order process with a rate independent of the [micelles]. The fission-growth $\left(k_{\text {fiss }}\right)$ process takes place through the breaking of one a micelle containing two probes into two small micelles "sub-micelles" followed by their fusion with an empty micelle or their growth by association with free macromolecules. This is a monomodal process and therefore exhibits first-order kinetics with a rate independent on [micelles]. On the other hand, fusion-fission requires the collision of one micelle bearing two probes with an empty micelle, the formation of a super-micelle, the exchange of the probes within this super-micelle, and fission of the super-micelle into two micelles containing each one probe. Because fusion process is a bimodal mechanism it exhibits second-order kinetics with a rate dependent on [micelles]. In the case where the concentration of empty micelles is larger than the full ones, the fusion-fission gives a pseudo-firstorder kinetics with a rate $k_{\text {fus }}$ [ [micelle]. The exchange rate can be written as $k_{\text {decay }}=k_{\text {exit }}+k_{\text {fiss }}+k_{\text {fus }}$ [micelle].

An insight on the role of probe diffusion on the exchange process can be taken from the first-order rate constant for excimer formation $(k \mathrm{Q})$ of this probe within the micelles. The $\mathrm{k}_{\mathrm{Q}}$ for this probe is found in the range of $7.5 \times 10^{6} \mathrm{~s}^{-1}$, which point out to the fluid aspect of the micelle core within the time scale of fusion and fission processes $10^{-3} \mathrm{~s}$ to $10^{3} \mathrm{~s}$ and therefore one can discard the probe diffusion as a potential limiting effect of the exchange process.

Fission of a loaded micelle can either split into two loaded micelles or in loaded and unloaded micelles. Only the first case can be seen as an event in the exchange experiment. Assuming 50/50\% happening, the calculated fission rate is $\mathrm{k}_{\mathrm{fiss}}=2 \mathrm{k}_{1}$. As the fusion of loaded and unloaded micelles is followed by a fission event, the fusion rate is $\mathrm{k}_{\text {fus }}=2 \mathrm{k}_{2}$. 
Probe exit-entry vs. assisted exchange or fusion-fission process. Probe molecule selection is crucial since it defines whether the kinetics occurs via the exit-entry process or the fusion-fission mechanisms. The exit-entry process is most likely dominated by the exit rate $\left(k_{\text {exit }}\right)$ of the probe from the micelles because the entry rate is a diffusion-controlled process with a rate in the order of $\left(k^{+} \approx 3\right.$ $\left.\times 10^{9} \mathrm{M}^{-1} \mathrm{~s}^{-1}\right) .{ }^{74}$ The exit rate can either be measured directly via a kinetic experiment or estimated from the equilibrium solubility limit as $k_{\text {exit }}=k^{+}\left[\mathrm{C}_{\mathrm{w}}\right] /\langle n\rangle$, where $\left[\mathrm{C}_{\mathrm{w}}\right]$ is the solubility limit of the probe in water and $\langle n\rangle$ is the average number of probe per micelles. $\left[\mathrm{C}_{\mathrm{w}}\right]$ decreases with decreasing the polarity of the probe in an Arrhenius way:

$$
[C w]=[C w]_{0} e^{-\mathrm{NE}_{\mathrm{CH}_{2}} / R T}
$$

where $\left[\mathrm{C}_{\mathrm{w}}\right]_{0}$ is the pyrene water solubility of 1 -acetylpyrene in the order of $10^{-6} \mathrm{M}^{-1}$, N and the number of the additional $\mathrm{CH}_{2}$ group. ${ }^{74-76}$ The excess energy induced by adding a $\mathrm{CH}_{2}$ group to the pyrene $E_{\mathrm{CH}_{2}}$ is reported to range between $4.3 \times 10^{-15} \mathrm{~mol} / \mathrm{L}$ and $4.7 \times 10^{-17} \mathrm{~mol} / \mathrm{L} .{ }^{77-79}$ If one considers $\langle n\rangle=1$ and neglects the effect of the corona viscosity on $\mathrm{k}^{+}$, it is possible to estimate the $\mathrm{k}_{\text {exit }}$ in a range between $1.3 \times 10^{-5} \mathrm{~s}^{-1}$ and $1.4 \times 10^{-7} \mathrm{~s}^{-1}$, at room temperature. Figure 5 shows that the probe exit rate is at least 100 times smaller than the lowest measured decay rate in the present copolymer. This demonstrates that the exit-entry process can safely be neglected in the exchange process of the present copolymer.

A second alternative method for estimating the probe exit rate is by measuring the probe water solubility, which unfortunately is inaccessible due to the lower detection limit of the fluorescence spectrometer. The third alternative is to recover the probe exit rate through kinetics measurements. Indeed, using the non-modified pyrene molecule as the probe, the dynamics is a first-order with no dependence on [micelles] and its exchange rate is dominated by the exit-entry rates of the dye $\left(10^{7} \mathrm{~s}^{-}\right.$ ${ }^{1}$ ), which is several orders of magnitude faster than the measured exchange rate. ${ }^{74}$ When increasing the length of alkyl molecule attached to the pyrene $\mathrm{pyC}_{6}, \mathrm{pyC}_{8}$, and $\mathrm{pyC}_{12}$ as the probe, the exit rate in the aqueous phase slows downs as the water solubility decreases but exhibits a first-order dynamic with no dependence on [micelles] and with an increasing rate as $10^{0.6} \cdot{ }^{74}$ For example, the exchange rate via exit-entry of $\mathrm{pyC}_{12}$ is found around $10^{2} \mathrm{~s}^{-1}$, which is insufficient to validate the slow fusion-fission mechanisms in the present block copolymer micelles. Yet, it was found to be sufficient to verify the fusion and fission in small molecular weight surfactant, such as alkyl-PEO. ${ }^{19,35,36}$ To estimate the exit rate of $\mathrm{pyC}_{18}$ from the micelle, a solution of ionic surfactant sodium dodecyl sulfate was used following the procedure described elsewhere ${ }^{74}$, in where the exchange was monitored at a very low ionic strength. 
Because the fusion and fission of SDS at low ionic strength occurs at an extremely slow rate, the exchange of this probe in this system can give a lower limit for the probe exit rate. Using this procedure, one can safely estimate a lower limit for the exit rate of this probe to be higher than several hours, which is much higher than the exchange of the Pluronic of this study. Because the exit rate of the $\mathrm{PyC}_{18}$ from the Pluronic micelles $\mathrm{k}_{\text {exit }}$ is negligible compared to the two collective mechanisms, it is possible to describe the exchange rate as $k_{\text {decay }}=k_{\text {fiss }}+k_{\text {fus }}$ [micelle].

The second-order kinetics described by the linear dependence on [micelles] is a bimodal process and can safely be attributed to the mechanism involving fusion-exchange-fission. This process takes place via the collision of a micelles/ $\mathrm{PyC}_{18}$ with an empty one, adhesion, fusion of the two micelles, and the exchange of solutes and fission of the large micelle into two proper micelles containing one probe each. The collision step cannot be the dominating mechanism because the diffusion-limited encounter rate, calculated using Smoluchowski equation, is more than $10^{9}$ times the measured $k_{\text {fus. }}$ The linear increase of $\mathrm{k}_{\text {decay }} v s$. [micelle] infers that fission of a super-micelle $\left(2 \mathrm{~N}_{\mathrm{agg}}\right)$ results from the fusion of two micelles, which is faster than $k_{\text {fiss }}$ of proper micelles. This is expected since the energy resulting from the fission of micelles of size $2 \mathrm{~N}_{\mathrm{agg}}$ is negative. ${ }^{27,37}$ If the fission rate of $2 \mathrm{~N}_{\mathrm{agg}}$ were similar to that of the proper micelle $\mathrm{N}_{\text {agg }}$, the $k_{\text {decay }}$ will level off at high concentration. Therefore, the rate of fusion is $k_{2}=k_{\text {fus. }}$.

Because the measured first-order process is much higher than the estimated exit rate $\mathrm{PyC}_{18}$, one can safely attribute this first-order kinetics to a mechanism involving fission-growth. This takes place via fission of a large micelle $\left(\mathrm{N}_{\mathrm{agg}}\right)$ containing two probes into two sub-micelles $\mathrm{N}_{1}$ and $\mathrm{N}_{\mathrm{agg}}-\mathrm{N}_{1}$, each containing one probe followed by their growth either via fusion with another small micelle or via insertion of free macromolecules. The size of the submicelles resulting from fission can vary from $\mathrm{N}_{\min }$ to $\mathrm{N}_{\text {agg }} / 2$ macromolecules, where $\mathrm{N}_{\text {min }}$ is the size of the smallest micelles that is hydrophobic enough to hold one $\mathrm{PyC}_{18}$. This raises the question as to what is the number of copolymer chains that one probe can transport? If one chain can englobe the probe and be transported out of the micelles $\left(\mathrm{N}_{\min }=1\right)$, this phenomenon could be called a "chain assisted probe exchange". One way to investigate the existence of this process is by taking a micelle solution containing two probes per micelle and diluting it to below its critical micelle concentration (CMC). Below $\mathrm{CMC}$, the copolymer chains go to the unimer state, and if a chain can hold a probe molecule, the excimer would decrease. This is not the case here because diluting the surfactant solution below $\mathrm{CMC}$ causes the $\mathrm{PyC}_{18}$ to remain in the aggregate form and precipitate. This infers that the hydrophobic group of one chain is unable to bear one $\mathrm{PyC}_{18}$ molecule. 
Therefore, the exchange of $\mathrm{PyC}_{18}$ is not likely to take place via "chain assisted probe exchange" and requires a competition of several copolymer chains to exit the micelle. Moreover, if a macromolecule can transport the probe $\left(\mathrm{N}_{\min }=1\right)$, the rate of the first-order kinetics will be in the same order of magnitude as the chain expulsion process. This process is not depicted here since the expulsion process is several order of magnitudes faster than the exchange rate measured here $k_{\text {expulsion }}\left(k_{\text {expulsion }} \approx 2000 \mathrm{~s}^{-}\right.$ 1). ${ }^{68,80}$ This suggests that the first-order kinetics measured is dominated by the fission of a large micelle into proper micelles with a size larger than a few macromolecules.

Temperature dependence of the exchange mechanism. Figure 4A shows the excimer intensity decays for P103 in the temperature range between 21 and $33^{\circ} \mathrm{C}$, where spherical micelles are formed. When increasing the temperature, the exchange is slowed down for all the concentrations tested. For all studied temperatures, the decay rate $k_{\text {decay }}$ undergoes a linear dependence on the concentration of empty micelles (Figure 5) with a finite intercept, which suggests a superposition of first and second order mechanisms. In Figure 6, the fission and fusion rates $k_{\text {fiss }}$ rates $k_{\text {fus }}$ vs. inverse temperature for aqueous P103 solutions is described. These rates are found to decrease with an increase in temperature throughout the spherical regime between 25 and $33^{\circ} \mathrm{C}$.

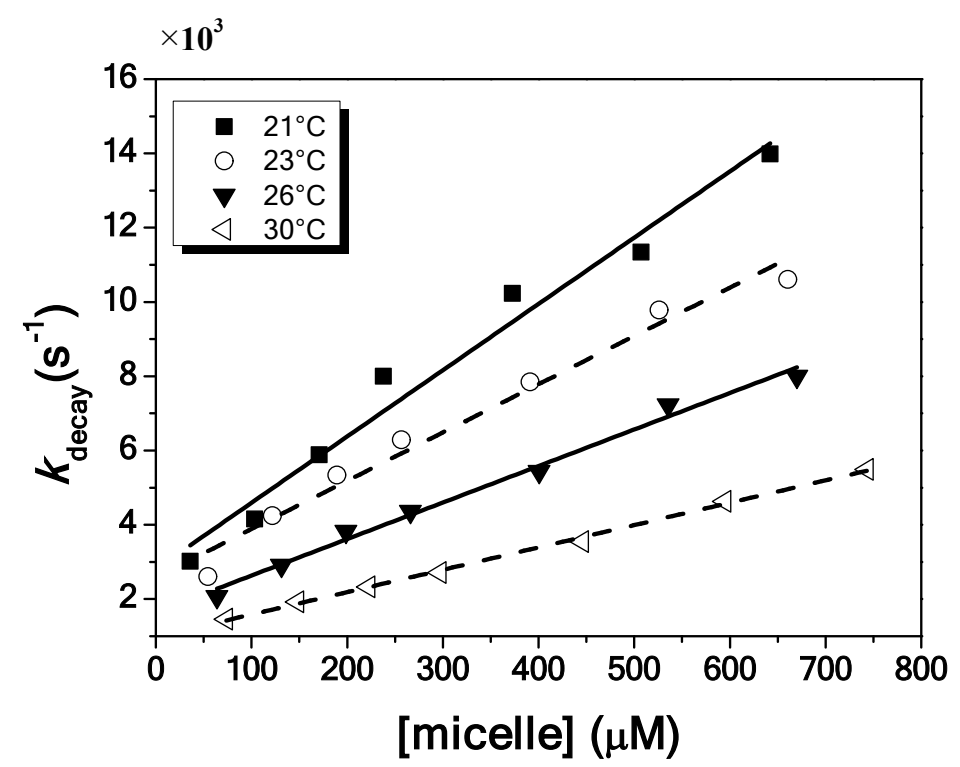

Figure 5. The relaxation rates $k_{\text {decay }}$ calculated from the fits of the decays of figures 3 and 4 to a single exponential expression, plotted versus the concentration of P103 empty micelles for various 
temperatures $21,23,26$ and $30^{\circ} \mathrm{C}$. The concentration of micelles is given by $([$ micelles $]=([\mathrm{P} 103]-$ $\mathrm{cmc}) / \mathrm{N}_{\mathrm{agg}}$.

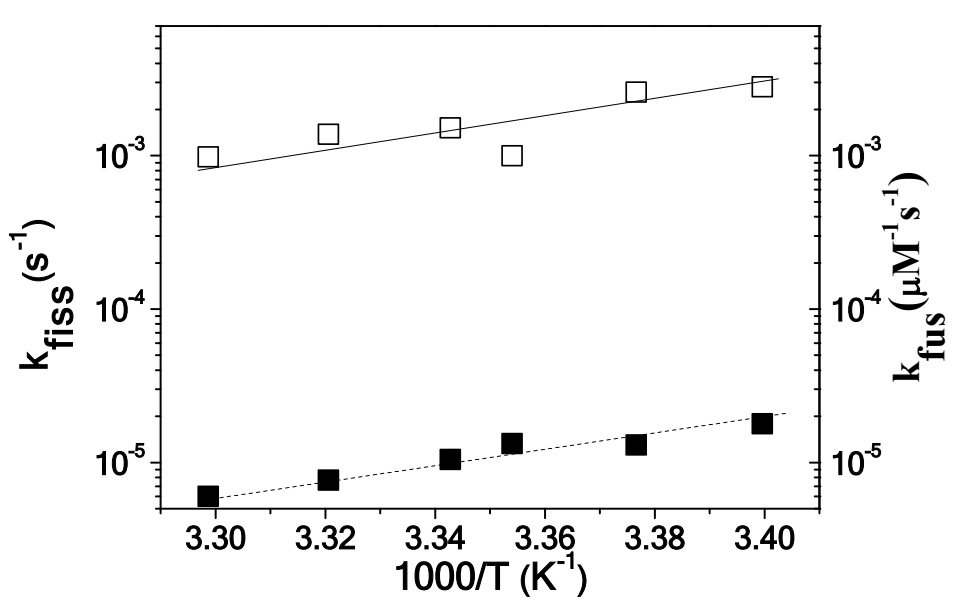

Figure 6. The rate of fission $k_{\text {fiss }}(\square)$ and the rate of fusion $k_{\text {fus }}(\boldsymbol{\square})$ vs. the inverse of absolute temperature for P103. $k_{\text {fus }}$ is calculated from the slope of $k_{\text {decay }}$ vs. [micelle] of figure $5 . k_{\text {fiss }}$ is calculated from the intercept of figure 5 .

The effect of the core-forming block length on the fusion and fission dynamics. Figure 5 and S2, Supplementary Information, shows the exchange decays of the P103, P84 and L64 at a temperature above their CMT in the range of sphere-like micelles, after decreasing the length of the core-forming block the exchange kinetics speed-up. ${ }^{37}$ The decays fit well to a single exponential expression for all copolymers investigated with a single exponential rate. $K_{\text {decay }}$ is found to follow the same trend as that observed for the P103 with a linear dependence on [micelles] and a constant intercept (Figure 7). This suggests the existence of the second-order process involving the fusion pathway and a second-order kinetic involving fission. Figure 8 shows the temperature dependence of the fusion and fission rates for the three copolymers. While the $k_{\text {fus }}$ and $k_{\text {fiss }}$ exhibits a negative temperature dependence for P103, they show a slight positive dependence for L64 and P84. The average values of $k_{\text {fus }}$ and $k_{\text {fiss }}$ increase by more than 5 orders of magnitude for the PPO length, ranging between 30 to 60 , which confirm the high sensitivity of the fusion and fission to the length of the core-forming block (Figure 9). 

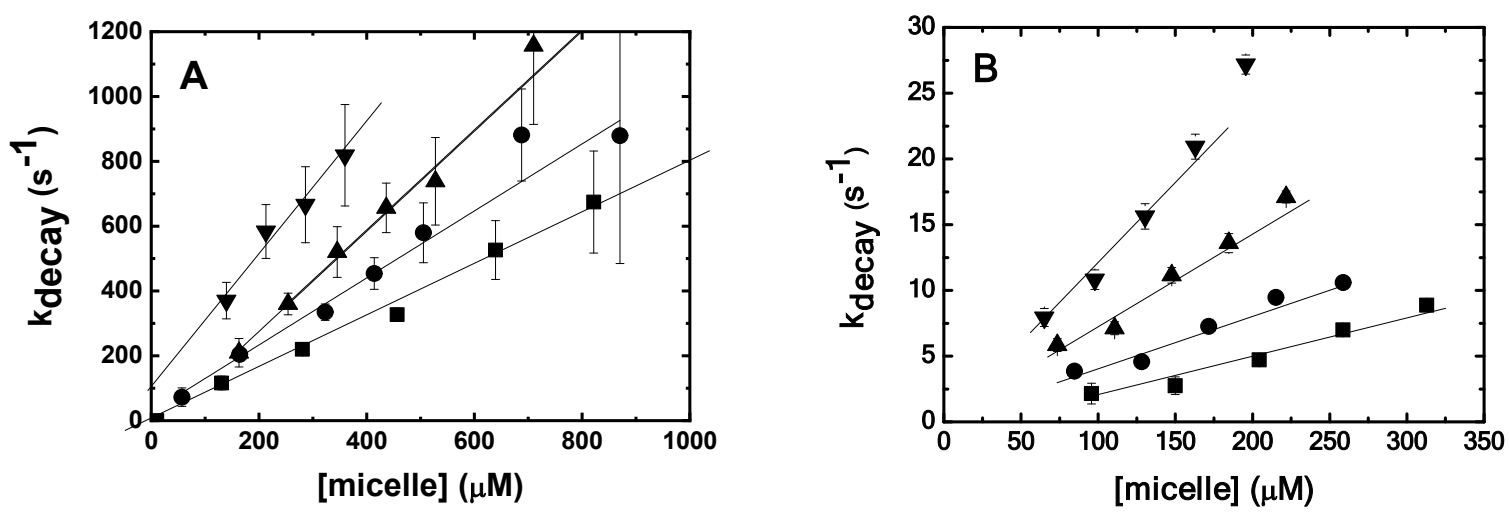

Figure 7. The relaxation rates $k_{\text {decay }}$ for (A) L64 and (B) P84 calculated from the fits of the decays to a single exponential expression, plotted versus the concentration of empty micelles for various

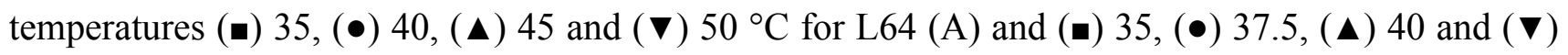
$42.5^{\circ} \mathrm{C}$ for P84 (B). The concentration of micelles is given by $\left([\right.$ micelles $]=([$ copolymer $\left.]-c m c) / \mathrm{N}_{\mathrm{agg}}\right)$.
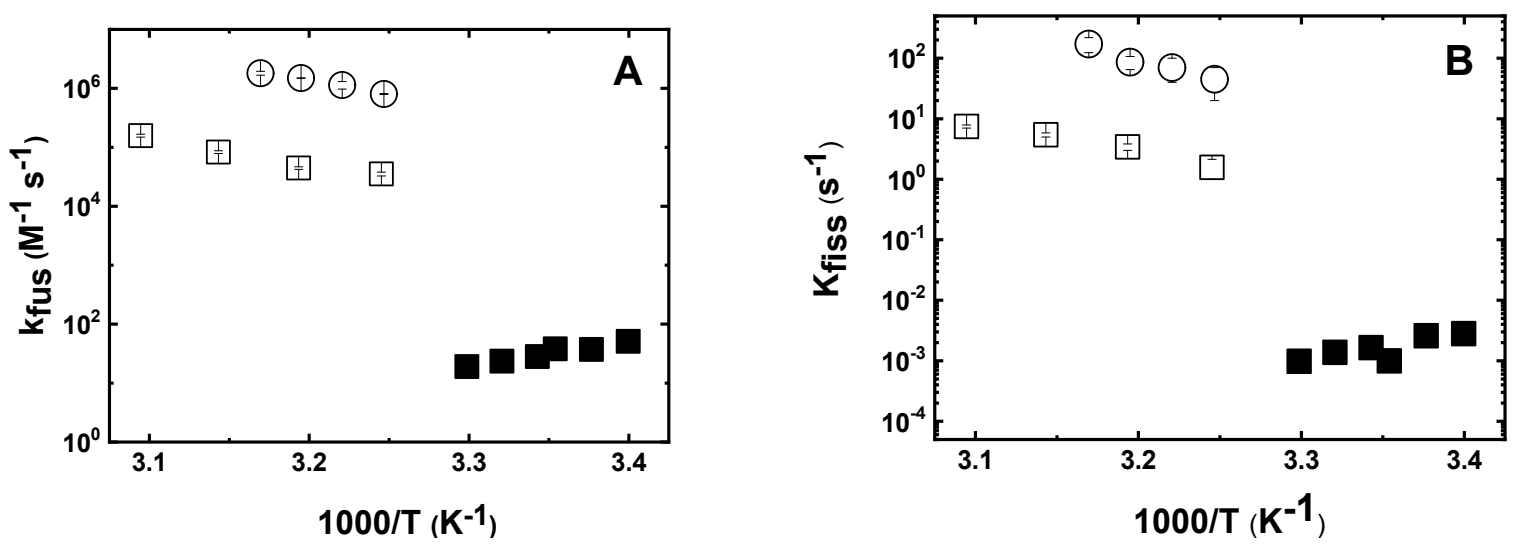

Figure 8. The rate of fusion $k_{\text {fus }}(\mathrm{A})$ and the rate of fission $k_{\text {fiss }}(\mathrm{B})$ vs. the inverse of absolute temperature for P103 ( $\mathbf{a}$ P84 (口) and L64 (०). $k_{\text {fus }}$ is calculated from the slope of $k_{\text {decay }}$ Vs. [micelle] of figure 5 and $7 . k_{\text {fiss }}$ is calculated from the intercept of figures 5 and 7. 

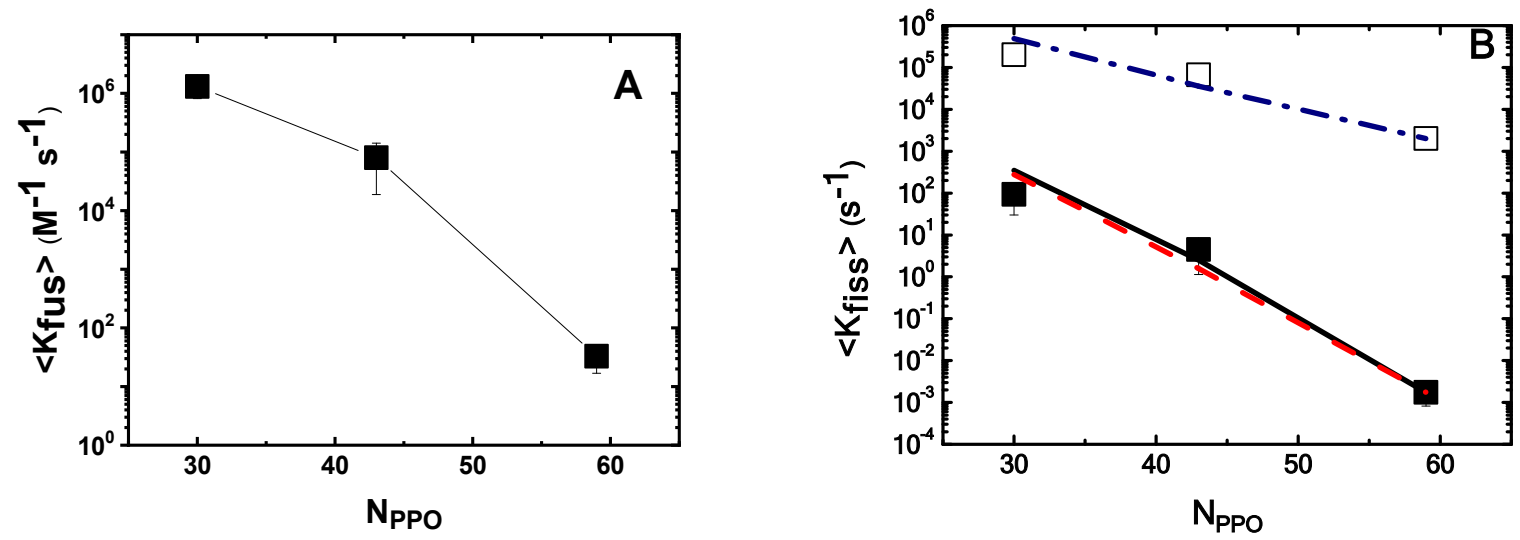

Figure 9. The dependence of the average rates of fusion $\left\langle k_{f u s}\right\rangle(\mathrm{A})$ and fission $\left\langle k_{f i s s}\right\rangle(\mathrm{B})$ on the length of the core forming block PPO. $\left\langle k_{f u s}\right\rangle$ and $\left\langle k_{f i s s}\right\rangle$ are calculated by averaging $k_{f u s}$ and $k_{f i s s}$ values from figure 8 for a limited range of temperature. Lines in Figure (B) are fits to equation 14 for the core limiting model with $\gamma=7 \mathrm{~N} . \mathrm{m}$ ( )and corona limiting one using $\gamma=7.8 \mathrm{~N} . \mathrm{m}$ (---) as well as for expulsion rate using equation 15 (--).

Fusion and fission vs. chain expulsion and insertion. Fusion/fission probably overlaps with the faster chain insertion/expulsion process, as rates of this process have been reported for temperature or pressure jump experiments. ${ }^{68}$ For example, $k_{\text {insertion }}$ and $k_{\text {expulsion }}$ rates were reported to be $\approx 2.4 \times 10^{8}$ $\mathrm{M}^{-1} \mathrm{~s}^{-1}$ and $2 \times 10^{5} \mathrm{~s}^{-1}$ for L64 at $40^{\circ} \mathrm{C}$ and $1.8 \times 10^{7} \mathrm{M}^{-1} \mathrm{~s}^{-1}$ and $6.7 \times 10^{4} \mathrm{~s}^{-1}$ for P84 at $27{ }^{\circ} \mathrm{C}{ }^{68}$ For $\mathrm{P} 103$, they were extrapolated from the same reference to be $5 \times 10^{6} \mathrm{~s}^{-1} \mathrm{M}^{-1}$ and $2 \times 10^{3} \mathrm{~s}^{-1}$ at room temperature. ${ }^{68,80}$

While fusion and fission are slower than insertion and expulsion, they can transfer $\mathrm{N}_{\text {agg }}$ chains between micelles for every event instead of one at a time, as demonstrated for insertion/expulsion, raising the question of chain homogenization efficiency via these two processes. Since insertion/expulsion is controlled by the expulsion step, the $\mathrm{k}_{\text {expultion }} / \mathrm{N}_{\text {agg }}$ can give an estimate of the rate for micelle renewal by insertion/expulsion, and $\mathrm{R}_{\text {rand }}=\mathrm{k}_{\text {expultion }} / \mathrm{N}_{\mathrm{agg}} / \mathrm{k}_{\text {decay }}$ would be a reliable parameter for comparing the effectiveness of the two mechanisms in renewing the micelle content (Figure 10). Insertion/expulsion accounts for most of the chain randomization between micelles in P103 copolymer with PPO60, since it can renew the micelles $10^{3}$ to $10^{4}$ times for every event of fusion/fission (Figure 10). $\mathrm{R}_{\text {rand }}$ decreases with decreasing PPO length and approaches seven times, in L64, at high micelle concentration (Figure 
10). This suggests that a decrease in the $\mathrm{Mw}$ of the core-forming block, favors the fusion/fission process, and makes it competitive with insertion/expulsion. However, randomization via fission is still 50 times slower than expulsion in L64, as seen at low [micelles] (Figure 10), but when increasing [micelles], fusion favors randomization and makes the collective mechanisms competitive with expulsion. Still, it is seven times slower, at least for the range of [micelles] investigated in this work. This shows that chains transport and randomization between micelles is mainly carried out via insertion and expulsion processes, while fusion and fission controls the morphological transformation of the micelles, and particularly the sphere-to-rod transition and probe vectorisation. ${ }^{6,14,15}$

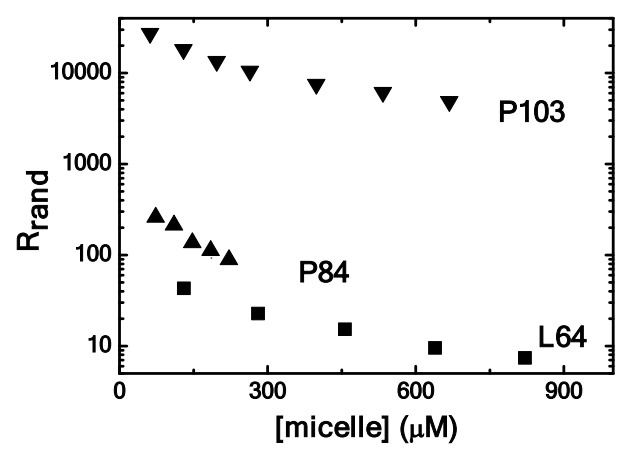

Figure 10. The plot of $R_{\text {rand }}$ parameter depicting the effectiveness of micelle renewal by insertion/expulsion and fusion/fission rate of micelle renewal by insertion/expulsion and fission/fusion plotted vs. [ micelle] for P103 ( $)$, P84( $\Delta$ ) and L64( $\boldsymbol{\nabla}) . \mathrm{R}_{\text {rand }}=\mathrm{k}_{\text {expulsion }} / \mathrm{N}_{\text {agg }} / \mathrm{k}_{\text {decay. }} \mathrm{k}_{\text {decay }}$ is taken from figures 5 and 7 at the temperatures where expulsion rate is reported.

\section{Energy barrier to fission in the spherical regime.}

While the fission rate $\mathrm{k}_{\text {fiss }}$ decreases with increasing temperatures for $\mathrm{P} 103$ between 25 and $33^{\circ} \mathrm{C}$, leading to a negative apparent activation energy of $-88.2 \mathrm{~kJ} / \mathrm{mol}$ in the Arrhenius fit, the fission rate slightly increases for P84 and L64 with an activation energy of $72.2 \mathrm{~kJ} / \mathrm{mol}$ and $157.7 \mathrm{~kJ} / \mathrm{mol}$, respectively (Figure 8). Predicting the dependence of the fission rate on the copolymer Mw and how it contrasts with expulsion is performed by evaluating the energy barriers to fission and expulsion. There are at least 4 energy barriers to fission: $i$ ) chains disentanglement dynamic within the core, $i i$ ) interfacial 
tension, iii) core elastic free energy due to chains extension, $i v$ ) corona elastic free energy due to chain extension. ${ }^{37}$ Although the copolymers investigated in this work are triblock, we used diblock copolymer models for crewcut and starlike micelles to get a first insight on the dependence of fission on the core molecular weight. ${ }^{27,37}$ One should bear in mind that the Halperin-Alexander model considers the limit of the solvent-free core in the case, which is clearly not the case of Pluronic copolymers where the core is hydrated to a certain limit depending on the temperature. ${ }^{69}$ The interfacial energy $\left(E_{\text {fiss }}{ }^{\text {inter }}\right)$ and the core elastic energy $\left(E_{\text {fiss }}{ }^{\text {core }}\right)$ dominates over the corona elastic energy in the first case leading to $\mathrm{E}_{\text {fiss }}=\mathrm{E}_{\text {fiss }}$ inter $+\mathrm{E}_{\text {fiss }}$ core (equations 5,6). On the other hand, for longer coronas, the corona extension dominates over the core extension leading to $\mathrm{E}_{\text {fiss }}=\mathrm{E}_{\text {fiss }}{ }^{\text {inter }}+\mathrm{E}_{\text {fiss }}{ }^{\text {corona }}$ (equations 5,7). The present results are analyzed in terms of these two models to consider that these copolymers are located between these two extreme cases. $\mathrm{E}_{\text {fiss }}{ }^{\text {inter }}, \mathrm{E}_{\text {fiss }}{ }^{\text {core }}, \mathrm{E}_{\text {fiss }}{ }^{\text {corona }}$ are taken from references 27 and 37. The $1 / 2$ term in $\mathrm{E}_{\text {fiss }}{ }^{\text {core }}, \mathrm{E}_{\text {fiss }}{ }^{\text {corona }}$ are added to take into consideration unidirectional extension. ${ }^{37}$

$$
\begin{aligned}
& E_{\text {fiss }}^{\text {inter }}=\frac{\alpha \chi(T) a^{2}}{K T} N_{P P O}{ }^{2 / 3} N_{\text {micelle }}{ }^{2 / 3}\left((x)^{2 / 3}+(1-x)^{2 / 3}-1\right) \\
& E_{\text {fiss }}^{\text {core }}=\frac{1}{2} N_{P P O}{ }^{-1 / 3} N_{\text {micelle }} 5 / 3\left((x)^{5 / 3}+(1-x)^{5 / 3}-1\right) \\
& E_{\text {fiss }}^{\text {corona }}=\frac{1}{2} N_{\text {micelle }}{ }^{3 / 2}\left((x)^{3 / 2}+(1-x)^{3 / 2}-1\right)
\end{aligned}
$$

where $\alpha$ is a prefactor, $\mathrm{N}_{\mathrm{PPO}}$ is the PPO number, $\gamma$ is the interfacial tension, $a$ is the Kuhn length of the PPO molecule $\mathrm{N}_{\text {micelle }}$ is the aggregation number of the breaking micelle and $\mathrm{x}=\mathrm{N}_{\text {micelle }}{ }^{1} / \mathrm{N}_{\text {micelle, }}$, with $\mathrm{N}_{\text {micelle }}{ }^{1}$ the size of the fragment. Values of $a \approx 4.6 \AA,{ }^{81,82}$ and $\alpha=(4 \pi)^{1 / 3} \cdot 3^{2 / 3} \approx 4.8$ were obtained for a spherical core but was reported to be 3.3.48,83 The $\mathrm{PPO} /$ water surface tension is temperature dependent with $\gamma(\mathrm{T}) \approx \mathrm{T}_{\mathrm{r}}^{2}$, where $\mathrm{T}_{\mathrm{r}}=\mathrm{T} / \theta-1$ and $\theta=195^{\circ} \mathrm{K} .{ }^{81}$ this is explained by a micelle core dehydration as temperatures increase, due to the reduction of the PPO water solubility. This leads to an increase in the interfacial tension $(\gamma(\mathrm{T}))$ of $\mathrm{PPO} /$ water between $4-21 \mathrm{mN} / \mathrm{m},{ }^{81}$ which explains the reduction of $\mathrm{k}_{\mathrm{fiss}}$ for $\mathrm{P} 103$ in the temperature range from 21 to $30^{\circ} \mathrm{C}$.

The micelles are distributed over a size distribution with an average size $\mathrm{N}_{\mathrm{agg}}$ and each micelle within this distribution $\left(\mathrm{N}_{\text {micelle }}\right)$ can undergo fission with a rate dependent on the sizes of the initial 
micelle and the resulting fragments. To get a first insight from these analyses we evaluated the fission energy only on micelles with equilibrium sizes $\mathrm{N}_{\text {micelle }}=\mathrm{N}_{\mathrm{agg}}$, for which $\mathrm{N}_{\mathrm{agg}}$ is derived by minimization of the free energy per chain $\left(E^{\text {inter }}+E^{\text {core }}\right.$ or $\left.E^{\text {inter }}+E^{\text {corona }}\right)$ with respect to $N_{\text {micelle }}$ and we consider only fissions events generating two equal micelles $\mathrm{x}=1 / 2$.

Replacing $\mathrm{N}_{\text {micelle }}$ with $\mathrm{N}_{\text {agg }}$ and $\mathrm{x}$ with $1 / 2$ leads $\mathrm{E}_{\text {fiss }}$ to equation 11 in the case of $\mathrm{E}_{\text {fiss }}=\mathrm{E}_{\text {fiss }}{ }^{\text {inter }}+$ $\mathrm{E}_{\text {fiss }}{ }^{\text {core }}$ and equation 12 in the case of $\mathrm{E}_{\text {fiss }}=\mathrm{E}_{\text {fiss }}{ }^{\text {inter }}+\mathrm{E}_{\mathrm{fiss}}{ }^{\text {corona }}$.

$$
\begin{aligned}
& \beta=\frac{\alpha \chi(T) a^{2}}{K T} \\
& N_{\text {agg }}=\beta N_{P P O} \\
& N_{\text {agg }}=\beta^{6 / 5} N_{P P O}^{4 / 5} \\
& E_{\text {fiss }}=N_{P P O}{ }^{\frac{4}{3}} \beta^{4 / 3}\left((2)^{\frac{1}{3}}-1+\frac{1}{2}\left(2^{-\frac{2}{3}}-1\right)\right) \\
& E_{\text {fiss }}=N_{P P O} O^{6 / 5} \beta^{9 / 5}\left((2)^{\frac{1}{3}}-1+\frac{1}{2}\left(2^{-\frac{1}{2}}-1\right)\right) \\
& E_{\text {expulsion }}=\beta N_{P P O}{ }^{\frac{2}{3}}
\end{aligned}
$$

Figures 7 and 9 , shows that $\mathrm{k}_{\text {fiss }}$ decreases by 5 orders of magnitude for $\mathrm{N}_{P P O}$ between 30 and 60 , while $k_{\text {expulsion }}$ decreases by 2 orders of magnitude, as a consequence of the stronger $\mathrm{N}_{\mathrm{PPO}}$ dependence of $\mathrm{E}_{\text {fiss }}$ $\mathrm{N}_{\mathrm{PPO}}{ }^{4 / 3}$ or $\mathrm{N}_{\mathrm{PPO}} 6 / 5$ compared $\mathrm{NPPO}^{2 / 3}$ of $\mathrm{E}_{\text {expulsion. }}$. A quantitative comparison with these models is carried out by estimating the $\mathrm{k}_{\text {fiss } 2}$ for various copolymers, assuming known value of $\mathrm{k}_{\mathrm{fiss}}$ for $\mathrm{P} 103$ and using either the crewcut model or the start-like model (equation 14). A similar procedure is also applied to the expulsion rate where $\mathrm{k}_{\text {expulsion }}$ is compared to the case of P103 following equation 15 . In both cases the $\mathrm{N}_{\mathrm{PPO}}$ dependence of $\mathrm{k}_{\text {fiss }}$ and $\mathrm{k}_{\text {expulsion }}$ prefactor is omitted in this analysis since it generates a weaker dependence; for example, the $k_{\text {expulsion }}$ prefactor for the crewcut case varies as $\mathrm{N}_{\mathrm{PPO}^{-2}}$, which adds a factor of 4 for NPPO between 60 and $30 .{ }^{37}$ However a complete analysis should consider this prefactor in the comparison. 


$$
\begin{aligned}
& k_{f i s s_{2}}=k_{f i s s_{1}} e^{E_{f i s s}^{1}-E_{f i s s}^{2}} \\
& k_{\text {expulsion }_{2}}=k_{\text {expulsion }} e^{E_{\text {expulsion }}^{1}-E_{\text {expulsion }}^{2}}
\end{aligned}
$$

In Figure $9 \mathrm{~b} \mathrm{k}_{\mathrm{fiss}}$ is found to follow the prediction for the crewcut case with $\gamma=7 \mathrm{mN} / \mathrm{m}$ and the starlike with $\gamma=7.8 \mathrm{mN} / \mathrm{m}$, which is a strong indication that fission rate can be predicted with these models. Figure $9 \mathrm{~b}$ shows that these parameters can also describe the dependence $\mathrm{k}_{\text {expulsion }}$ on $\mathrm{N}_{\mathrm{PPO}}$ but with $\gamma=6.4 \mathrm{mN} / \mathrm{m}$.

\section{Energy barrier to fusion dynamic in the spherical regime.}

Figure $7 \mathrm{a}$ shows the fusion rate $k_{\text {fus }}$ dependence on temperature in the spherical regime for three copolymers with core lengths between 30 and 60 and figure $9 \mathrm{a}$ depicts the $\mathrm{k}_{\text {fus }}$ dependence on PPO core length. These figures point out two sets of clues regarding the fusion mechanism: first, $\mathrm{k}_{\text {fus }}$ for each of the three copolymers investigated, exhibit the same temperature dependence as $\mathrm{k}_{\text {fiss }}$; $\mathrm{k}_{\text {fus }}$ decreases for P103 with an apparent activation energy of $(-79.4 \mathrm{~kJ} / \mathrm{mol})$ and increases in P84 and L64 with an activation energy of $93.3 \mathrm{~kJ} / \mathrm{mol}$ and $98.6 \mathrm{~kJ} / \mathrm{mol}$ for P84 and L64 (Figure $7 \mathrm{a}$ and b). This constitutes a first indication that fusion shears some aspects with the barrier energy to fission. Second, $\mathrm{k}_{\text {fus }}$ decreases by 5 orders of magnitude when $\mathrm{N}_{\text {PPO }}$ increases from 30 to 60 in the same trend as $\mathrm{k}_{\text {fiss }}$ (figure 9a), which again emphasizes the role of the core-forming block and the interfacial tension in the fusion process. Such behavior is not exclusive to these copolymers but was also observed in small surfactant molecules. ${ }^{84}$ However, it is not trivial to explain such behavior using a model where the activation free energy is solely attributed to the corona interaction because this predicts an activation energy of $\mathrm{E}_{\text {fus }} \sim \mathrm{N}_{\text {micelle }}{ }^{3 / 2}$ for two equal size micelles $\left(\mathrm{N}_{\text {micelle }}\right)$ in the starlike case and $E_{\text {fus }} \sim N_{\text {micelle }}{ }^{2}$. $N_{P E O}{ }^{2} / N_{P P O}$ for the thin corona case. ${ }^{27,37}$ These results point out to the need to consider the role of the interfacial energy and the core elastic energy in estimating the energy barrier to fusion. ${ }^{84}$

Exponential behavior vs. logarithmic kinetic. Although the PEO-PPO-PPO of this study are polydisperse $_{2}$ with a polydispersity exceeding 1.7 , they still exhibit an almost exponential fusion/fission kinetics for all conditions investigated here with the exception close to $C M C$ or $C M T$, but also no 
exponential tendencies are observed (Figure 4, S2, Supplmentary information). This in contrast with the highly nonexponential chain insertion/expulsion kinetics reported in well segregated block copolymer micelles such as PEO-PBO, which was explained by the strong sensitivity of the expulsion activation energy to chain polydispersity (equation 13). ${ }^{30,48}$ However, the core crystallinity and polymer architecture were also found to play a role in the nonexponential behavior of the insertion/expulsion kinetics. ${ }^{25,50,85,86}$

To gain insight into the role of chain polydispersity in fusion/fission kinetics, the decays are simulated by considering chain polydispersity in the activation energy (equations 11, 12). The exchange decay can be written as $I_{E} / I_{E_{0}}=\left[\exp \left(-\left(k_{f i s s}+k_{f u s}[\right.\right.\right.$ micelles $\left.\left.\left.]\right) \mathrm{t}\right)\right]$. Because fusion and fission exhibit a similar $\mathrm{N}_{\mathrm{PPO}}$ dependence, we use the same activation energy for $\mathrm{k}_{\text {fiss }}$ and $\mathrm{k}_{\text {fus. }}$.

$$
I_{E}=I_{E_{0}} \sum P\left(N_{P P O}\right) e^{-t^{*} e^{-E_{f i s s}}}
$$

Where $\mathrm{P}\left(N_{P P O}\right)$ is a gaussian distribution of the core chain length with a variance $\sigma=0.1 \mathrm{M}_{\mathrm{w}}$ as a typical example and $\mathrm{t}^{*}$ a nondimensional time $\left(\mathrm{t}^{*}=\mathrm{t} . \mathrm{k}_{\mathrm{fiss}}{ }^{0}\right.$, with $\mathrm{k}_{\text {fiss }}{ }^{0}$ the inverse of the time to reach activated state). The calculated decays using equation 16 were found to be highly nonexponential in a similar way as those for chain expulsion kinetic. ${ }^{30,48}$

There are several plausible explanations for the exponential behavior for fission/fusion kinetics: $i$ ) the particular morphology of this triblock copolymer could play a role in this behavior. ${ }^{50} \mathrm{ii}$ ) The relatively low Mw of such copolymer could attribute to it surfactant properties instead of copolymer micelles properties. iii) The low interfacial energy of the PPO core, which limits the core/corona segregation and could, generates particular micelle architecture. $i v$ ) Fission/fusion takes place on all the micelles within the size distribution and each event has its own activation energy that depends on the size of the interacting micelles., This could pre-average the activation energy leading to an apparent exponential behavior. v) Insertion/expulsion occurs much faster than fusion/fission which randomizes the micelles content several times during one event of fusion/fission leading to an averaging of the activation energy. Indeed, the last possibility was tested by calculating the decay by averaging $\mathrm{E}_{\mathrm{fiss}}$ in equation 16 to take into account the role of the rapid micelle randomization via insertion/expulsion (equation 17). This leads to $\left\langle E_{f i s s}\right\rangle$ values independent of the molecular weight distribution and monoexponential decays (Figure 11). This suggests that the fast chain randomization during fission makes these micelles energetically homogeneous leading to a fission/fusion exponential kinetic. 


$$
I_{E}=I_{E 0} \sum \mathrm{P}\left(N_{P P O}\right) \mathrm{e}^{-\mathrm{t}^{*} \mathrm{e}^{-\sum P\left(N_{P P O}\right) E_{f i s s}}}
$$

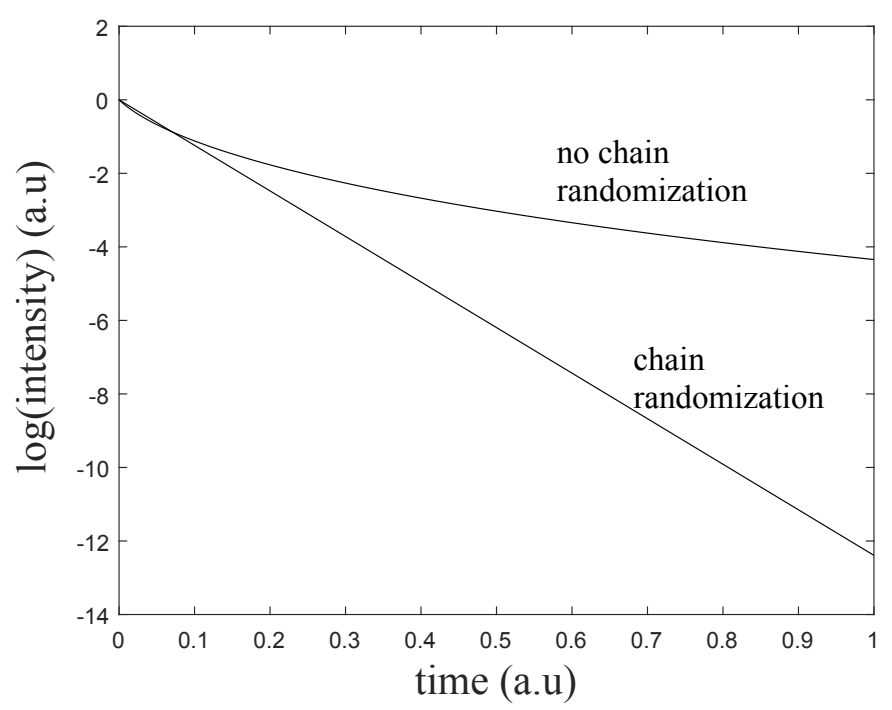

Figure 11. The calculated decay $\log \left(\mathrm{I}_{\mathrm{E}}\right)$ vs. normalized time $\mathrm{t}^{*}$ for the case of non-randomization (up) and chain randomization by expulsion/insertion (down). A similar result is obtained for fission process. This is obtained using a copolymer polydispersity of 1.1 .

\section{CONCLUSIONS.}

This paper describes fusion and fission mechanisms at equilibrium in the PEOxPPOyPEOx triblock copolymer micelles in the spherical regime for various temperatures and core block length PPO. A fluorescence technique with a highly hydrophobic probe is used to monitor these two processes. We show that fusion and fission take place between proper micelles at equilibrium. Fission is found to be highly sensitive to the core block length with a rate kiss decreasing by 5 order of magnitudes for NPPO between 30 and 60. The fission rate dependence on the core length is reasonably accounted for using diblock models for the thin corona and star-like micelle. This shows that fission is mainly 
dominated by interfacial tension as predicted by Haleperin and Alexander. The difference between fission and expulsion rates dependence on the core-forming block is also predicted in terms of these models. On the other hand, fusion and fission are found to exhibit the same temperature and core length dependence, which infers that the interfacial tension energy plays an important role in the fusion kinetic. This finding suggests that one needs to complete the existing models by considering the interfacial tension in the fusion process. The fusion and fission are 106 times slower than insertion and expulsion at the highest PPO length investigated here (60) and the difference between these processes decreases with decreasing the core length. Yet the micelle randomization remains dominated by insertion/expulsion for all the cases investigated here. Fusion/fission yields to a single exponential decay even in highly polydispersed copolymers, in contrast to what one would expect if the activation energy depends on the polymer polydispersity. This was explained by taking into consideration the rapid chain randomization between micelles to average the activation energy and attenuate the effect of chain polydispersity. This result suggests that fusion and fission take place on homogeneous micelles.

\section{ASSOCIATED CONTENT}

\section{Supporting Information}

The Supporting Information is available free of charge at

Time-resolved excimer formation fluorescence decays of pyrene in a solution of triblock copolymer P103; Time-scan excimer decays after stopped-flow mixing a copolymer micelle solution containing $\mathrm{PyC}_{18}$ with an empty micelle solution for P84 and L64. (PDF)

\section{ACKNOWLEDGMENT}

This work was supported by the joint program ECOS-Nord M05P02E, MO6-P03 of the ministry of research and education (France). We acknowledge M. Karrouch, E. Faivre, F. Hugenell and Dr. Hélène Galliard for their technical support and Dr. Tania Diaz Vidal for her help. Single Photon timing equipment was a donation form Raoul ZANA. The Laboratoire Rhéologie et Procédés is part of the LabEx Tec 21 (Investissements d'Avenir - grant agreement n\degree ANR-11-LABX-0030) and of the 
PolyNat Carnot Institut (Investissements d'Avenir - grant agreement nldegree ANR-11-CARN-030$01)$.

\section{AUTHOR INFORMATION}

\section{Corresponding Author}

*Email; yahya.rharbi@univ-grenoble-alpes.fr

\section{REFERNCES}

(1) Hamley, I. Block Copolymers in Solution: Fundamentals and Applications; John Wiley \& Sons, Ltd: Chichester, UK, 2005. https://doi.org/10.1002/9780470016985.

(2) Lazzari, M.; Liu, G.; Lecommandoux, S. Block Copolymers in Nanoscience; 2008. https://doi.org/10.1002/9783527610570.

(3) Alexandridis, P.; Lindman, B. Amphiphilic Block Copolymers. In Encyclopedia of Membranes; Springer Berlin Heidelberg: Berlin, Heidelberg, 2016; pp 69-69. https://doi.org/10.1007/978-3662-44324-8_100011.

(4) Mai, Y.; Eisenberg, A. Self-Assembly of Block Copolymers. Chem. Soc. Rev. 2012, 41 (18), 5969-5985. https://doi.org/10.1039/c2cs35115c.

(5) M Kahlweit, M. Kinetics of Formation of Association Colloids. J. Colloid Interface Sci. 1982, 90 (1), 2-99. https://doi.org/10.1016/0021-9797(82)90401-5.

(6) Mysona, J. A.; Mccormick, A. V; Morse, D. C. Mechanism of Micelle Birth and Death. Phys. Rev. Lett. 2019, 123. https://doi.org/10.1103/PhysRevLett.123.038003.

(7) Nicolai, T.; Colombani, O.; Chassenieux, C. Dynamic Polymeric Micelles versus Frozen Nanoparticles Formed by Block Copolymers. Soft Matter 2012, 6 (14), 3111-3118. https://doi.org/10.1039/B925666K.

(8) Sun, X.; Liu, D.; Pei, S.; Li, K.; Wan, W. Versatile Method to Expand the Morphology Library of Block Copolymer Solution Self-Assemblies with Tubular Structures. ACS Macro Lett. 2016, 5 (10), 1180-1184. https://doi.org/10.1021/acsmacrolett.6b00672.

(9) Jensen, G. V.; Lund, R.; Narayanan, T.; Pedersen, J. S. Transformation from Globular to Cylindrical Mixed Micelles through Molecular Exchange That Induces Micelle Fusion. J. Phys. Chem. Lett. 2016, 7 (11), 2039-2043. https://doi.org/10.1021/acs.jpclett.6b00767. 
(10) Kelley, E.; Murphy, R.; Seppala, J.; Smart, T.; Hann, S.; Sullivan, M.; Epps, T. Size Evolution of Highly Amphiphilic Macromolecular Solution Assemblies via a Distinct Bimodal Pathway. Nat. Commun. 2014, 5, 3599. https://doi.org/10.1038/ncomms4599.

(11) Lund, R.; Willner, L.; Richter, D.; Lindner, P.; Narayanan, T. Kinetic Pathway of the Cylinderto-Sphere Transition in Block Copolymer Micelles Observed in Situ by Time-Resolved Neutron and Synchrotron Scattering. ACS Macro Lett. 2013, 2 (12), 1082-1087. https://doi.org/10.1021/mz400521p.

(12) Santos, J. L.; Herrera-Alonso, M. Kinetically Arrested Assemblies of Architecturally Distinct Block Copolymers. $\quad$ Macromolecules $2014, \quad 47 \quad$ (1), 137-145. https://doi.org/10.1021/ma402047e.

(13) Johnson, B. K.; Prud'homme, R. K. Mechanism for Rapid Self-Assembly of Block Copolymer Nanoparticles. Phys. Rev. Lett. 2003, 91 (11). https://doi.org/10.1103/PhysRevLett.91.118302.

(14) Hayward, R. C.; Pochan, D. J. Tailored Assemblies of Block Copolymers in Solution: It Is All about the Process. Macromolecules. April 27, 2010, pp 3577-3584. https://doi.org/10.1021/ma9026806.

(15) Jain, S.; Bates, F. S. Consequences of Nonergodicity in Aqueous Binary PEO-PB Micellar Dispersions. Macromolecules 2004, 37 (4), 1511-1523. https://doi.org/10.1021/ma035467j.

(16) Aniansson, E. A. G.; Wall, S. N. Kinetics of Step-Wise Micelle Association. J. Phys. Chem. 1974, 78 (10), 1024-1030. https://doi.org/10.1021/j100603a016.

(17) Aniansson, E. A. G.; Wall, S. N. Kinetics of Step-Wise Micelle Association and Dissociation. In Chemical and Biological Applications of Relaxation Spectrometry; Wyn-Jones E. (eds), Ed.; Springer, Dordrecht: Gothenburg, Sweden, 1975; Vol. 18, p 16. https://doi.org/https://doi.org/10.1007/978-94-010-1855-5_26.

(18) Waton, G.; Michels, B.; Zana, R. Dynamics of Block Copolymer Micelles in Aqueous Solution. Macromolecules 2001, 34 (4), 907-910. https://doi.org/10.1021/ma001170z.

(19) Rharbi, Y.; Winnik, M. A.; Hahn, K. G. Kinetics of Fusion and Fragmentation Nonionic Micelles: Triton X-100. Langmuir 1999, $15 \quad$ (14), 4697-4700. https://doi.org/10.1021/1a990064r.

(20) Lessner, E.; Teubner, M.; Kahlweit, M. Relaxation Experiments in Aqueous Solutions of Ionic Micelles. 1. Theory and Experiments on the System Water-Sodium Tetradecyl Sulfate-Sodium Perchlorate. J. Phys. Chem. 1981, 85 (11), 1529-1536. https://doi.org/10.1021/j150611a014. 
(21) Aniansson, E. A. G.; Wall, S. N. Kinetics of Step-Wise Micelle Association. Correction and Improvement. J. Phys. Chem. 1975, 79 (8), 857-858. https://doi.org/10.1021/j100575a019.

(22) Aniansson, E. A. G.; Wall, S. N.; Almgren, M.; Hoffmann, H.; Kielmann, I.; Ulbricht, W.; Zana, R.; Lang, J.; Tondre, C. Theory of the Kinetics of Micellar Equilibria and Quantitative Interpretation of Chemical Relaxation Studies of Micellar Solutions of Ionic Surfactants. J. Phys. Chem. 1976, 80 (9), 905-922. https://doi.org/10.1021/j100550a001.

(23) Wall, S. N.; Aniansson, G. E. A. Numerical Calculations on the Kinetics of Stepwise Micelle Association. J. Phys. Chem. 1980, 84 (7), 727-736. https://doi.org/10.1021/j100444a009.

(24) Lessner, E.; Teubner, M.; Kahlweit, M. Relaxation Experiments in Aqueous Solutions of Ionic Micelles. 2. Experiments on the System H20-NaDS-NaCI04 and Their Theoretical Interpretation; 1981; Vol. 85.

(25) Zinn, T.; Willner, L.; Pipich, V.; Richter, D.; Lund, R. Molecular Exchange Kinetics of Micelles: Corona Chain Length Dependence. ACS Macro Lett. 2016, 5 (7), 884-888. https://doi.org/10.1021/acsmacrolett.6b00395.

(26) Lu, J.; Bates, F. S.; Lodge, T. P. Addition of Corona Block Homopolymer Retards Chain Exchange in Solutions of Block Copolymer Micelles. Macromolecules 2016, 49 (4), 1405-1413. https://doi.org/10.1021/acs.macromol.5b02395.

(27) Dormidontova, E. E. Micellization Kinetics in Block Copolymer Solutions: Scaling Model. Macromolecules 1999, 32 (22), 7630-7644. https://doi.org/10.1021/ma9809029.

(28) Denkova, A. G.; Mendes, E.; Coppens, M. O. Kinetics and Mechanism of the Sphere-to-Rod Transition of Triblock Copolymer Micelles in Aqueous Solutions. J. Phys. Chem. B 2009, 113 (4), 989-996. https://doi.org/10.1021/jp807513k.

(29) Landazuri, G.; Fernandez, V. V. A.; Soltero, J. F. A.; Rharbi, Y. Kinetics of the Sphere-to-Rod like Micelle Transition in a Pluronic Triblock Copolymer. J. Phys. Chem. B 2012, 116 (38), 11720-11727. https://doi.org/10.1021/jp3009089.

(30) Choi, S. H.; Lodge, T. P.; Bates, F. S. Mechanism of Molecular Exchange in Diblock Copolymer Micelles: Hypersensitivity to Core Chain Length. Phys. Rev. Lett. 2010, 104 (4). https://doi.org/10.1103/PhysRevLett.104.047802.

(31) Prhashanna, A.; Chen, S. B. Chain Exchange Kinetics between Linear ABA-Type Triblock Copolymer Micelles. Polymer (Guildf). 2017, $118, \quad$ 22-29. https://doi.org/10.1016/j.polymer.2017.04.049. 
(32) Schantz, A. B.; Saboe, P. O.; Sines, I. T.; Lee, H. Y.; Bishop, K. J. M.; Maranas, J. K.; Butler, P. D.; Kumar, M. PEE-PEO Block Copolymer Exchange Rate between Mixed Micelles Is Detergent and Temperature Activated. Macromolecules 2017, 50 (6), 2484-2494. https://doi.org/10.1021/acs.macromol.6b01973.

(33) Li, X.; Liu, Y.; Wang, L.; Deng, M.; Liang, H. Fusion and Fission Pathways of Vesicles from Amphiphilic Triblock Copolymers: A Dissipative Particle Dynamics Simulation Study. Phys. Chem. Chem. Phys. 2009, 11 (20), 4051. https://doi.org/10.1039/b817773b.

(34) Lin, Y.-L.; Chang, H.-Y.; Sheng, Y.-J.; Tsao, H.-K. Self-Assembled Polymersomes Formed by Symmetric, Asymmetric and Side-Chain-Tethered Coil-Rod-Coil Triblock Copolymers. Soft Matter 2014, 10 (11), 1840. https://doi.org/10.1039/c3sm52916a.

(35) Rharbi, Y.; Li, M.; Winnik, M. A.; Hahn, K. G. Temperature Dependence of Fusion and Fragmentation Kinetics of Triton X-100 Micelles. J. Am. Chem. Soc. 2000, 122 (26), 62426251. https://doi.org/10.1021/ja9942585.

(36) Rharbi, Y.; Bechthold, N.; Landfester, K.; Salzman, A.; Winnik, M. A. Solute Exchange in Synperonic Surfactant Micelles. Langmuir 2003, $19 \quad$ (1), 10-17. https://doi.org/10.1021/la020221d.

(37) Halperin, A.; Alexander, S. Polymeric Micelles: Their Relaxation Kinetics. Macromolecules 1989, 22 (5), 2403-2412. https://doi.org/10.1021/ma00195a069.

(38) Lessner, E.; Teubner, M.; Kahlweit, M. Relaxation Experiments in Aqueous Solutions of Ionic Micelles. 2. Experiments on the System Water-Sodium Dodecyl Sulfate-Sodium Perchlorate and Their Theoretical Interpretation. J. Phys. Chem. 1981, 85 (21), 3167-3175. https://doi.org/10.1021/j150621a033.

(39) Chang, H.-Y.; Lin, Y.-L.; Sheng, Y.-J.; Tsao, H.-K. Structural Characteristics and Fusion Pathways of Onion-Like Multilayered Polymersome Formed by Amphiphilic Comb-Like Graft Copolymers. Macromolecules 2013, 46 (14), 5644-5656. https://doi.org/10.1021/ma400667n.

(40) Choucair, A. A.; Kycia, A. H.; Eisenberg, A. Kinetics of Fusion of Polystyrene-b-Poly(Acrylic Acid) Vesicles in Solution. Langmuir 2003, 19 (4), 1001-1008. https://doi.org/10.1021/la026187k.

(41) Takahashi, R.; Narayanan, T.; Yusa, S. I.; Sato, T. Kinetics of Morphological Transition between Cylindrical and Spherical Micelles in a Mixture of Anionic-Neutral and CationicNeutral Block Copolymers Studied by Time-Resolved SAXS and USAXS. Macromolecules 
2018, 51 (10), 3654-3662. https://doi.org/10.1021/acs.macromol.8b00101.

(42) Zhang, L.; Eisenberg, A. Thermodynamic vs Kinetic Aspects in the Formation and Morphological Transitions of Crew-Cut Aggregates Produced by Self-Assembly of Polystyreneb -Poly(Acrylic Acid) Block Copolymers in Dilute Solution. Macromolecules 1999, 32 (7), 2239-2249. https://doi.org/10.1021/ma981039f.

(43) Lund, R.; Willner, L.; Pipich, V.; Grillo, I.; Lindner, P.; Colmenero, J.; Richter, D. Equilibrium Chain Exchange Kinetics of Diblock Copolymer Micelles: Effect of Morphology. Macromolecules 2011, 44 (15), 6145-6154. https://doi.org/10.1021/ma200532r.

(44) Xie, M.; Wang, S.; Singh, A.; Cooksey, T. J.; Marquez, M. D.; Bhattarai, A.; Kourentzi, K.; Robertson, M. L. Fluorophore Exchange Kinetics in Block Copolymer Micelles with Varying Solvent-Fluorophore and Solvent-Polymer Interactions. Soft Matter 2016, 12 (29), 6196-6205. https://doi.org/10.1039/c6sm00297h.

(45) Smith, C. K.; Liu, G. Determination of the Rate Constant for Chain Insertion into Poly(Methyl Methacrylate)-Block-Poly(Methacrylic Acid) Micelles by a Fluorescence Method. Macromolecules 1996, 29 (6), 2060-2067. https://doi.org/10.1021/ma951338u.

(46) Burke, S. E.; Eisenberg, A. Kinetics and Mechanisms of the Sphere-to-Rod and Rod-to-Sphere Transitions in the Ternary System PS310-b-PAA52/Dioxane/Water. Langmuir 2001, 17 (21), 6705-6714. https://doi.org/10.1021/la010640v.

(47) Wang, E.; Lu, J.; Bates, F. S.; Lodge, T. P. Effect of Corona Block Length on the Structure and Chain Exchange Kinetics of Block Copolymer Micelles. Macromolecules 2018, 51 (10), 35633571. https://doi.org/10.1021/acs.macromol.7b02732.

(48) Lund, R.; Willner, L.; Stellbrink, J.; Lindner, P.; Richter, D. Logarithmic Chain-Exchange Kinetics of Diblock Copolymer Micelles. Phys. Rev. Lett. 2006, 96 (6), 068302. https://doi.org/10.1103/PhysRevLett.96.068302.

(49) Zhao, D.; Ma, Y.; Lodge, T. P. Exchange Kinetics for a Single Block Copolymer in Micelles of Two Different Sizes. Macromolecules 2018, $51 \quad$ (6), 2312-2320. https://doi.org/10.1021/acs.macromol.7b02550.

(50) Lu, J.; Bates, F. S.; Lodge, T. P. Remarkable Effect of Molecular Architecture on Chain Exchange in Triblock Copolymer Micelles. Macromolecules 2015, 48 (8), 2667-2676. https://doi.org/10.1021/acs.macromol.5b00294.

(51) Lund, R.; Willner, L.; Richter, D.; Dormidontova, E. E. Equilibrium Chain Exchange Kinetics 
of Diblock Copolymer Micelles: Tuning and Logarithmic Relaxation. Macromolecules 2006, 39 (13), 4566-4575. https://doi.org/10.1021/ma060328y.

(52) Won, Y.; Davis, H.; Bates, F. Molecular Exchange in PEO- PB Micelles in Water. Macromolecules, 2003, 36 (3), 953-955. https://doi.org/10.1021/ma021439+.

(53) García Daza, F. A.; Bonet Avalos, J.; Mackie, A. D. Logarithmic Exchange Kinetics in Monodisperse Copolymeric Micelles. Phys. Rev. Lett. 2017, 118 (24), 248001-1 to 248001248005. https://doi.org/10.1103/PhysRevLett.118.248001.

(54) Schaeffel, D.; Kreyes, A.; Zhao, Y.; Landfester, K.; Butt, H. J.; Crespy, D.; Koynov, K. Molecular Exchange Kinetics of Diblock Copolymer Micelles Monitored by Fluorescence Correlation Spectroscopy. ACS Macro Lett. 2014, $3 \quad$ (5), 428-432. https://doi.org/10.1021/mz500169n.

(55) Rharbi, Y. Fusion and Fragmentation Dynamics at Equilibrium in Triblock Copolymer Micelles. Macromolecules 2012, 45 (24), 9823-9826. https://doi.org/10.1021/ma3018298.

(56) Olah, G. Friedel-Crafts and Related Reactions: Acylation and Related Reactions. 2 V; Interscience Publishers, 1964, Ed.; Elsevier: Pensilvania, 1964. https://doi.org/https://doi.org/10.1016/B978-0-08-012210-6.50106-X.

(57) Maestri, M.; Infelta, P. P.; Grätzel, M. Kinetics of Fast Light-Induced Redox Processes in Micellar Systems: Intramicellar Electron Transfer. J. Chem. Phys. 1978, 69 (4), 1522-1526. https://doi.org/10.1063/1.436724.

(58) Infelta, P. P. Fluorescence Quenching in Micellar Solutions and Its Application to the Determination of Aggregation Numbers. Chem. Phys. Lett. 1979, 61 (1), 88-91. https://doi.org/10.1016/0009-2614(79)85092-7.

(59) Tachiya, M. Application of a Generating Function to Reaction Kinetics in Micelles. Kinetics of Quenching of Luminescent Probes in Micelles. Chem. Phys. Lett. 1975, 33 (2), 289-292. https://doi.org/10.1016/0009-2614(75)80158-8.

(60) Boens, N.; Novikov, E.; Van der Auweraer, M. Compartmental Analysis in Photophysics: Kinetics and Identifiability of Models for Quenching of Fluorescent Probes in Micelles. Math. Biosci. 2007, 209 (2), 624-643. https://doi.org/10.1016/j.mbs.2007.04.006.

(61) Foster, B.; Cosgrove, T.; Hammouda, B. Pluronic Triblock Copolymer Systems and Their Interactions with Ibuprofen. Langmuir 2009, $25 \quad$ (12), 6760-6766. https://doi.org/10.1021/la900298m. 
(62) Nolan, S. L.; Phillips, R. J.; Cotts, P. M.; Dungan, S. R. Light Scattering Study on the Effect of Polymer Composition on the Structural Properties of PEO-PPO-PEO Micelles. J. Colloid Interface Sci. 1997, 191 (2), 291-302. https://doi.org/10.1006/jcis.1997.4918.

(63) Kadam, Y.; Yerramilli, U.; Bahadur, A.; Bahadur, P. Micelles from PEO-PPO-PEO Block Copolymers as Nanocontainers for Solubilization of a Poorly Water Soluble Drug Hydrochlorothiazide. Colloids Surfaces $B$ Biointerfaces 2011, 83 (1), 49-57. https://doi.org/10.1016/j.colsurfb.2010.10.041.

(64) Alexander, S.; De Vos, W. M.; Castle, T. C.; Cosgrove, T.; Prescott, S. W. Growth and Shrinkage of Pluronic Micelles by Uptake and Release of Flurbiprofen: Variation of PH. Langmuir 2012, 28 (16), 6539-6545. https://doi.org/10.1021/la204262w.

(65) Nivaggioli, T.; Tsao, B.; Alexandridis, P.; Hatton, T. A. Microviscosity in Pluronic and Tetronic Poly(Ethylene Oxide)-PolyCpropylene Oxide) Block Copolymer Micelles. Langmuir 1995, 11 (1), 119-126. https://doi.org/10.1021/la00001a023.

(66) Liu, Y.; Chen, S. H.; Huang, J. S. Small-Angle Neutron Scattering Analysis of the Structure and Interaction of Triblock Copolymer Micelles in Aqueous Solution. Macromolecules 1998, 31 (7), 2236-2244. https://doi.org/10.1021/ma971253o.

(67) Almgren, M.; Bahadur, P.; Jansson, M.; Li, P.; Brown, W.; Bahadur, A. Static and Dynamic Properties of a (PEOPPOPEO) Block Copolymer in Aqueous Solution. J. Colloid Interface Sci. 1992, 151 (1), 157-165. https://doi.org/10.1016/0021-9797(92)90247-J.

(68) Zana, R.; Marques, C.; Johner, A. Dynamics of Micelles of the Triblock Copolymers Poly(Ethylene Oxide)-Poly(Propylene Oxide)-Poly(Ethylene Oxide) in Aqueous Solution. $A d v$. Colloid Interface Sci. 2006, 123-126, 345-351. https://doi.org/10.1016/j.cis.2006.05.011.

(69) Yang, L.; Alexandridis, P.; Steytler, D. C.; Kositza, M. J.; Holzwarth, J. F. Small-Angle Neutron Scattering Investigation of the Temperature-Dependent Aggregation Behavior of the Block Copolymer Pluronic L64 in Aqueous Solution. Langmuir 2000, 16 (23), 8555-8561. https://doi.org/10.1021/la000008m.

(70) McDonald, C.; WONG, C. K. The Effect of Temperature on the Micellar Properties of a Polyoxypropylene-Polyoxyethylenepolymer in Water. J. PHARM. PHARMACOL 1974, 26 (7), $556-557$.

(71) Thurn, T.; Couderc-Azouani, S.; Bloor, D. M.; Holzwarth, J. F.; Wyn-Jones, E. Ultrasonic Relaxation in Micellar Solutions of Nonionic Triblock Copolymers. Langmuir 2003, 19 (10), 
4363-4370. https://doi.org/10.1021/la020987d.

(72) Infelta, P. P.; Grätzel, M. Statistics of Solubilizate Distribution and Its Application to Pyrene Fluorescence in Micellar Systems. A Concise Kinetic Model. J. Chem. Phys. 1979, 70 (1), 179186. https://doi.org/10.1063/1.437218.

(73) Hilczer, M.; Barzykin, A. V.; Tachiya, M. Theory of the Stopped-Flow Method for Studying Micelle Exchange Kinetics. Langmuir 2001, 17 (14), 4196-4201. https://doi.org/10.1021/la001285w.

(74) Rharbi, Y.; Winnik, M. A. Salt Effects on Solute Exchange and Micelle Fission in Sodium Dodecyl Sulfate Micelles below the Micelle-to-Rod Transition. J. Phys. Chem. B 2003, 107 (7), 1491-1501. https://doi.org/10.1021/jp020842f.

(75) Taisne, L.; Walstra, P.; Cabane, B. Transfer of Oil between Emulsion Droplets. J. Colloid Interface Sci. 1996, 184 (2), 378-390. https://doi.org/10.1006/jcis.1996.0632.

(76) Li, L.; Thayumanavan, S. Environment-Dependent Guest Exchange in Supramolecular Hosts. Langmuir 2014, 30 (41), 12384-12390. https://doi.org/10.1021/la502760c.

(77) Kozlov, M. Y.; Melik-Nubarov, N. S.; Batrakova, E. V.; Kabanov, A. V. Relationship between Pluronic Block Copolymer Structure, Critical Micellization Concentration and Partitioning Coefficients of Low Molecular Mass Solutes. Macromolecules 2000, 33 (9), 3305-3313. https://doi.org/10.1021/ma991634x.

(78) Tolls, J.; Van Dijk, J.; Verbruggen, E. J. M.; Hermens, J. L. M.; Loeprecht, B.; Schüürmann, G. Aqueous Solubility-Molecular Size Relationships: A Mechanistic Case Study Using C 10 - to C 19 -Alkanes. J. Phys. Chem. A 2002, 106 (11), 2760-2765. https://doi.org/10.1021/jp011755a.

(79) Ferguson, A. L.; Debenedetti, P. G.; Panagiotopoulos, A. Z. Solubility and Molecular Conformations of N-Alkane Chains in Water. J. Phys. Chem. B 2009, 113 (18), 6405-6414. https://doi.org/10.1021/jp811229q.

(80) Kexpulsion and Kinsertion Are Extrapolated from Figure 1 and Figure 2. of Reference "Zana, R.; Marques C.; Johner, A. A. Dynamics of Micelles of the Triblock Copolymers Poly(Ethylene Oxide)-Poly(Propylene Oxide)-Poly(Ethylene Oxide) in Aqueous Solution.; 2006; Vol. 345.

(81) Linse, P.; Hatton, T. A. Mean-Field Lattice Calculations of Ethylene Oxide and Propylene Oxide Containing Homopolymers and Triblock Copolymers at the Air/Water Interface. Langmuir 1997, 13 (15), 4066-4078. https://doi.org/10.1021/la9620871.

(82) Lettow, J. S.; Lancaster, T. M.; Glinka, C. J.; Ying, J. Y. Small-Angle Neutron Scattering and 
Theoretical Investigation of Poly ( Ethylene Oxide ) - Poly ( Propylene Oxide ) - Poly ( Ethylene Oxide ) Stabilized Oil-in-Water Microemulsions. Langmuir 2005, 21 (13), 5738-5746.

(83) Lund, R.; Willner, L.; Stellbrink, J.; Lindner, P.; Richter, D. Erratum: Logarithmic ChainExchange Kinetics of Diblock Copolymer Micelles (Physical Review Letters (2006) 96 (068302)). Phys. Rev. Lett. 2010, $104 \quad$ (4), https://doi.org/10.1103/PhysRevLett.104.049902.

(84) Rharbi, Y.; Karrouch, M.; Richardson, P. Fusion and Fission Inhibited by the Same Mechanism in Electrostatically Charged Surfactant Micelles. Langmuir 2014, 30 (27), 7947-7952. https://doi.org/10.1021/1a501465v.

(85) Zinn, T.; Willner, L.; Pipich, V.; Richter, D.; Lund, R. Effect of Core Crystallization and Conformational Entropy on the Molecular Exchange Kinetics of Polymeric Micelles. ACS Macro Lett. 2015, 4 (6), 651-655. https://doi.org/10.1021/acsmacrolett.5b00197.

(86) Zinn, T.; Willner, L.; Lund, R.; Pipich, V.; Richter, D. Equilibrium Exchange Kinetics in NAlkyl-PEO Polymeric Micelles: Single Exponential Relaxation and Chain Length Dependence. Soft Matter 2012, 8 (3), 623-626. https://doi.org/10.1039/c1sm06809a. 